\title{
Using Publicly Available Information to Predict Cyber Failures
}

\section{Parisa Badalkhani}

A thesis submitted to the Faculty of Graduate Studies and Research in partial fulfillment of the requirement for the degree of the

Master of Applied Science

in

Technology Innovation Management

Faculty of Engineering and Design

Carleton University

Copyright $(\mathcal{C}$ December 2016, Parisa Badalkhani 


\begin{abstract}
This research examines the use of an anticipatory method and publicly available newsworthy information on ten past cyber failures of critical infrastructures in the United States to predict cyber failures of networks and systems of technology startups.

The Anticipatory Failure Determination (AFD) method was modified to enable the use of publicly available information. A list of the resources that were used to cause the ten cyber failures in critical infrastructures was produced and used to make predictions of failure scenarios of a stack of open source software. Finally, the factors that enable and constrain the use of the AFD method to predict cyber failures in technology startups were specified.
\end{abstract}

Junior engineers, designers, contractors and other stakeholders of cyber systems as well as government policy makers will be interested in outcome of this research to predict potential cyber failures for proactive mitigation. 


\section{Acknowledgement}

Firstly, I would like to express my sincere gratitude to my advisor Prof. Bailetti for the continuous support, for his patience, motivation, and immense knowledge. I could not have imagined having a better advisor and mentor for my study.

I would like to thank my professors: Prof. Craigen, Prof. Weiss, Prof. Muegge, and Prof. Westerlund for their supports and precious ideas for improving this study.

I deeply grateful to my family: my parents, my brothers, and sister for supporting me spiritually throughout my life.

I must express my very profound gratitude to my spouse, Hamidreza and my sweetheart, Parham for their understanding and unfailing encouragement throughout my years of study. This accomplishment would not have been possible without them. Thank you. 


\section{TABLE OF CONTENTS}

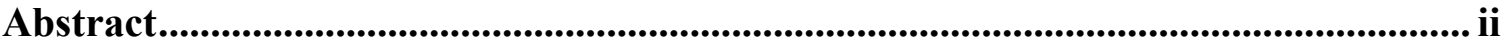

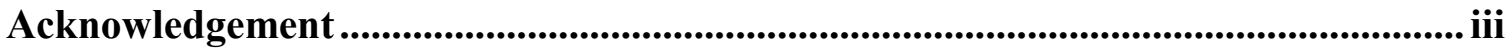

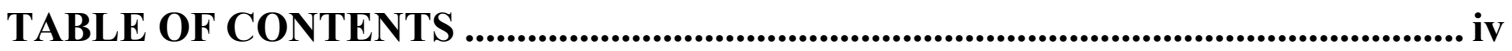

LIST OF TABLES ................................................................................................................ vi

LIST OF FIGURES ..................................................................................................... viii

$1 \quad$ Introduction ......................................................................................................................... 1

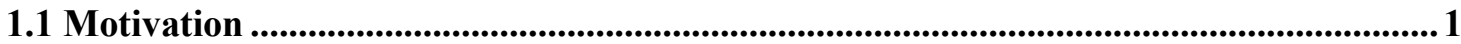

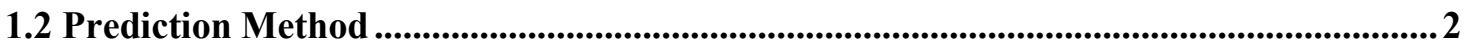

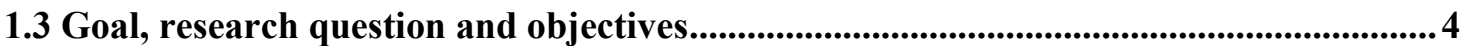

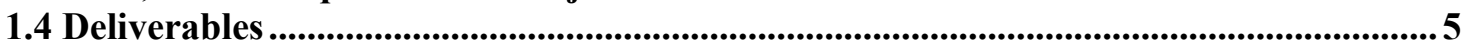

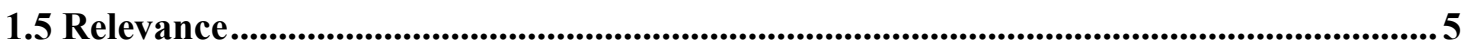

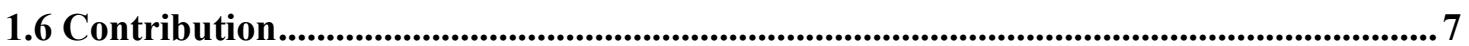

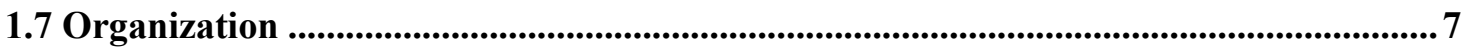

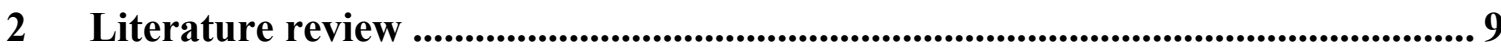

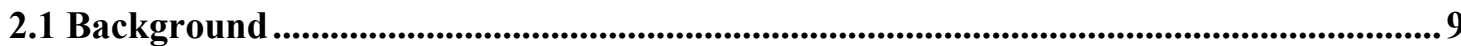

2.2 Failure anticipation in critical infrastructure ................................................................... 10

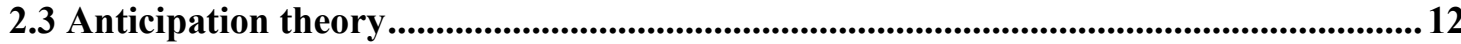

2.4 Anticipatory failure determination method .................................................................... 13

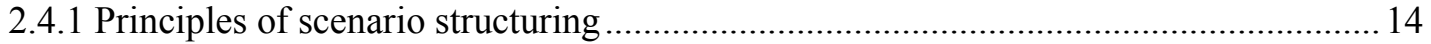

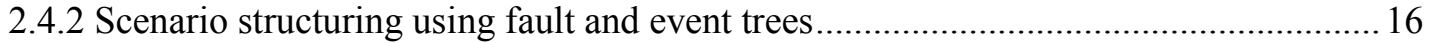

2.4.3 AFD Applications: Failure Analysis (AFD-1) and Failure Prediction (AFD-2).......... 17

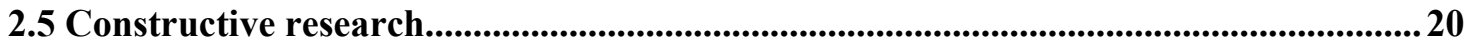

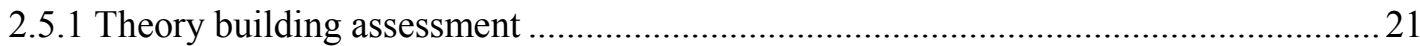

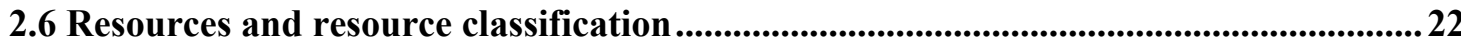

$3 \quad$ Method .......................................................................................................................... 26

3.1 Motivation, research question, objectives, and the approach.....................................26

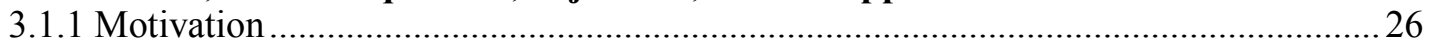

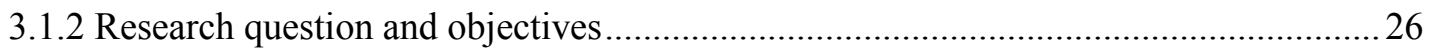

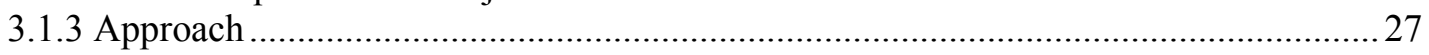

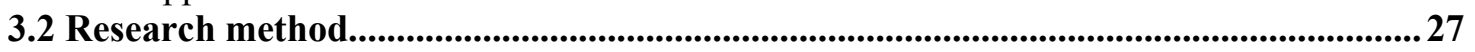

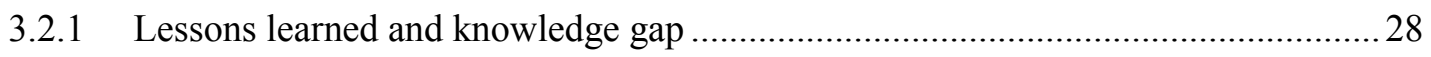

3.2.2 A process that uses anticipatory method and publicly available information about

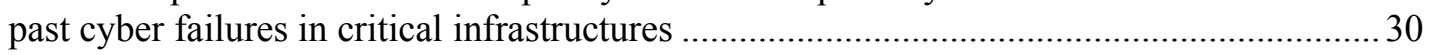

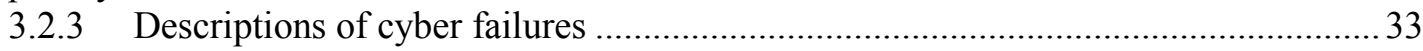

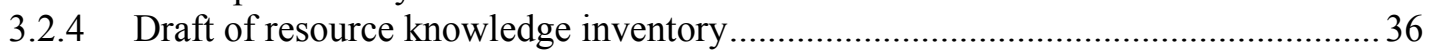

3.2.5 Revised process and resource knowledge inventory as per experts' review .............39 
3.3 Summary

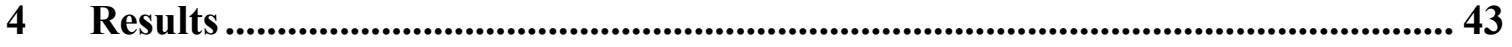

4.1 Sample, timeline and study period ..........................................................................................43 4.2 The Process used publicly available information about past cyber failures in critical

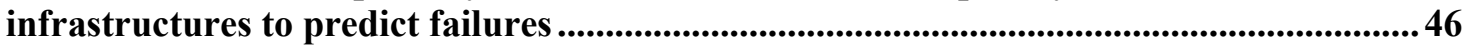

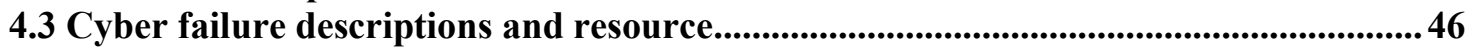

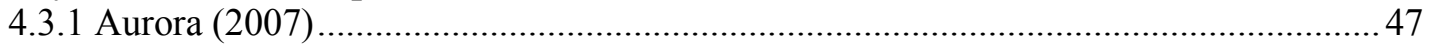

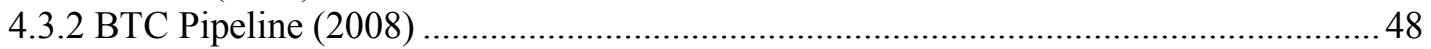

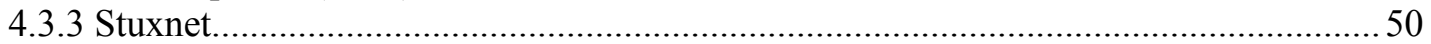

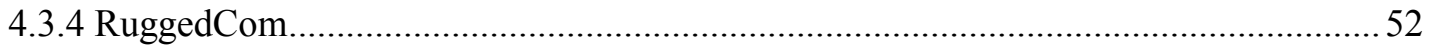

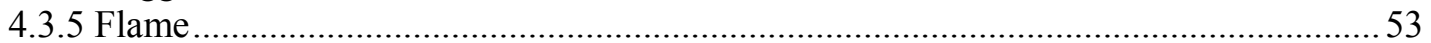

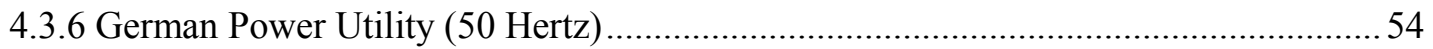

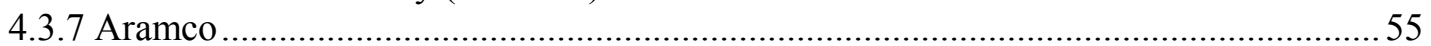

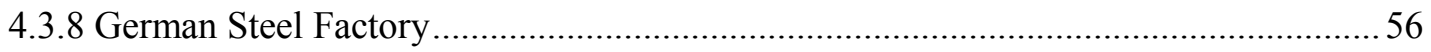

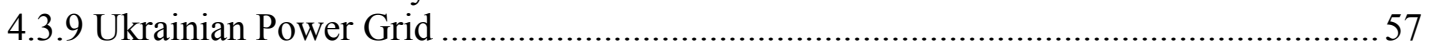

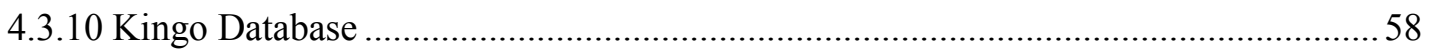

4.4 Draft of resource knowledge inventory .....................................................................60

4.5 Revised process and revised resource knowledge inventory ............................................66

4.6 Potential resources that may cause failure and failure scenarios for a sample system66

4.7 Enablers and constraints of using AFD method to predict failures using publicly

available information .......................................................................................................................69 6

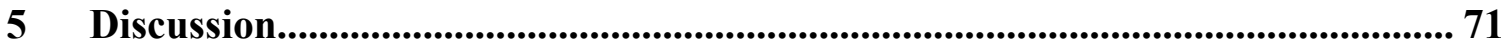

5.1 Challenges of developing the resource knowledge inventory .........................................71

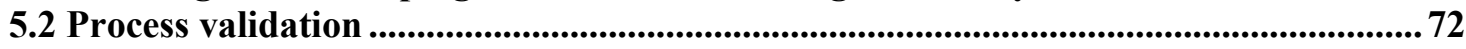

5.3 Adoption problem.......................................................................................................................... 72

5.4 Using resource knowledge inventory in operation level................................................. 73

5.5 Predictions of cyber failure scenarios in a sample system ................................................. 73

5.6 Link the results of research to the literature............................................................... 74

6 Conclusion, limitations, and suggestions for future research ............................ 75

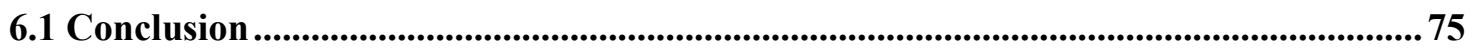

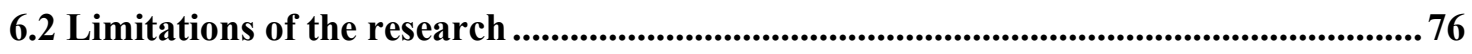

6.3 Suggestions for future research ...................................................................................................... 77

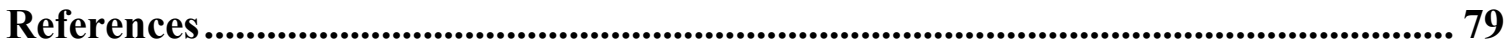




\section{LIST OF TABLES}

Table 1- Theory-building criteria and assessment developed by Arend et al. (2015) ...... 22

Table 2-Research Method ...................................................................................... 28

Table 3- Classification of resources in cyber failures in critical infrastructure ............... 38

Table 4- The ten cyber failure in critical infrastructures identified in criteria................ 44

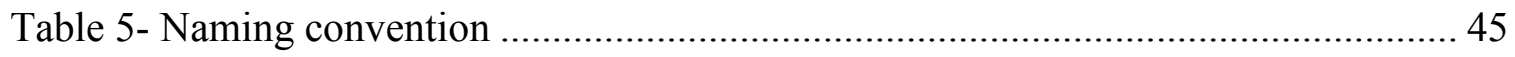

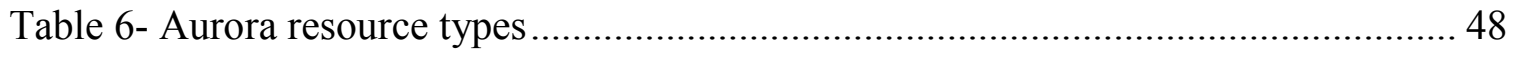

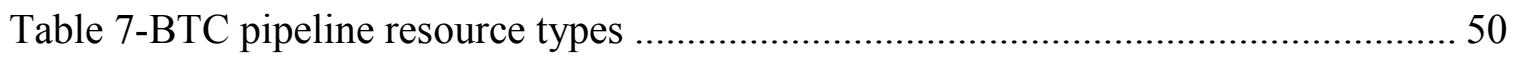

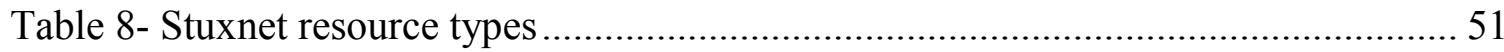

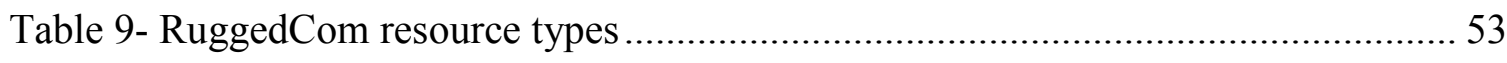

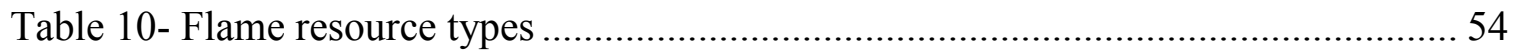

Table 11- German power utility (50 Hertz) resource types ...................................... 55

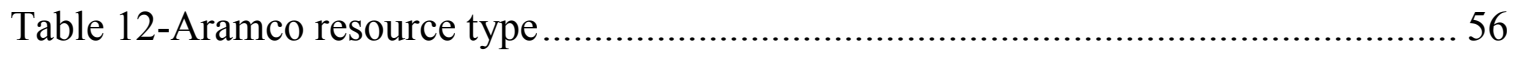

Table 13- German steel factory resource types................................................... 57

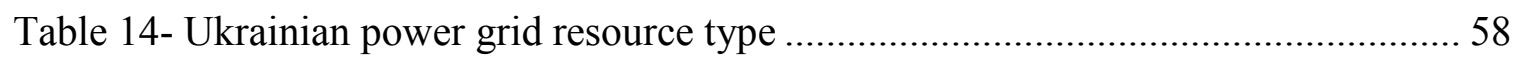

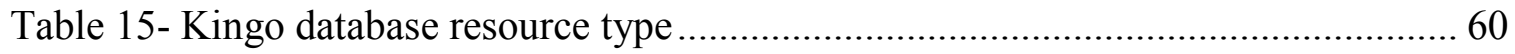

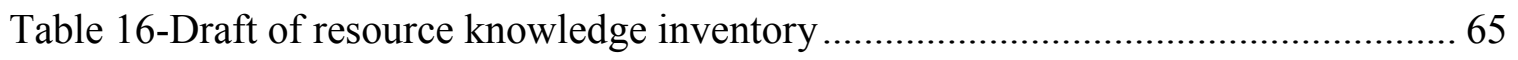

Table C. 1-List of the resource of the Aurora cyber failure identified based on the

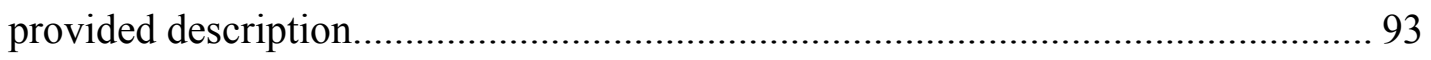

Table C. 2- List of the resource of the BTC-Pipeline cyber failure identified based on the

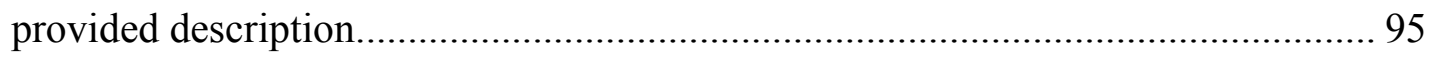


Table C. 3- List of the resource of the Stuxnet cyber failure identified based on the

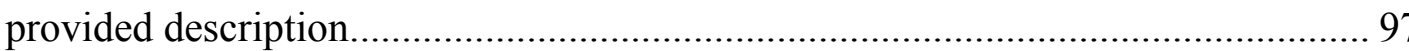

Table C. 4- List of the resource of the RuggedCom cyber failure identified based on the provided description 98

Table C. 5- List of the resource of the Flame cyber failure identified based on the provided description 100

Table C. 6- List of the resource of the German Power Utility (50 Hertz) cyber failure identified based on the provided description 101

Table C. 7- List of the resource of the Aramco cyber failure identified based on the provided description

Table C. 8- List of the resource of the German Steel Factory cyber failure identified based on the provided description 105

Table C. 9- List of the resource of the Ukrainian Electrical Grid cyber failure identified based on the provided description 107

Table C. 10- List of the resource of the Kingo Database cyber failure identified based on the provided description. 108 


\section{LIST OF FIGURES}

Figure 1- Rosen's definition of Anticipatory system............................................ 13

Figure 2-Branches from two different trees can end at the same end state (Kaplan et

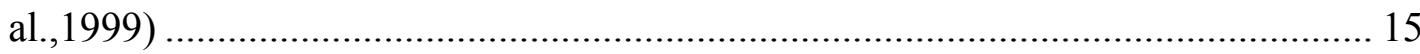

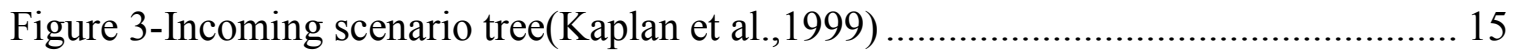

Figure 4-"mixed" Scenario tree(Kaplan et al.,1999).................................................... 16

Figure 5- Combined Use of Forward and Backward Trees(Kaplan et al., 1999) ............. 16

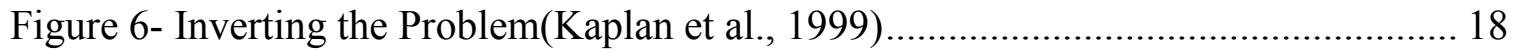

Figure 7- Inverting problem from "How does it happen?" to " How can it be produced?"

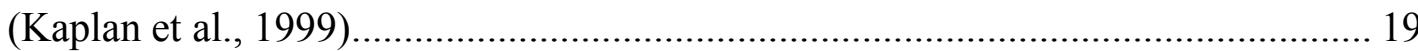

Figure 8- Utilization of resources(Kaplan et al., 1999) ............................................. 19

Figure 9-AFD schematic to identify the steps that can be carried out using publicly

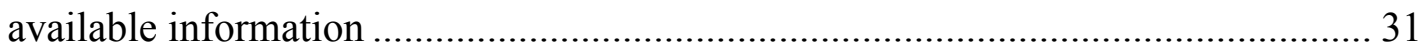

Figure 10-The process used in this research to predict failures ................................... 33

Figure 11- Timeline of past cyber failure in critical infrastructure included in the sample

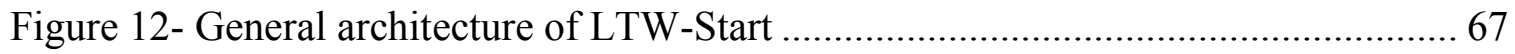

Figure C. 1-Failure analysis (scenario tree) for Aurora cyber failure ........................... 92

Figure C. 2- Failure analysis (scenario tree) for the BTC-Pipeline cyber failure............. 94

Figure C. 3- Failure analysis (scenario tree) for the Stuxnet cyber failure ..................... 96

Figure C. 4- Failure analysis (scenario tree) for the RuggedCom cyber failure ............... 98 
Figure C. 5- Failure analysis (scenario tree) for the Flame cyber failure

Figure C. 6- Failure analysis (scenario tree) for the German Power Utility (50 Hertz) cyber failure 101

Figure C. 7- Failure analysis (scenario tree) for the Aramco cyber failure. 102

Figure C. 8- Failure analysis (scenario tree) for the German Steel Factory cyber failure

Figure C. 9- Failure analysis (scenario tree) for the Ukrainian Electrical Grid cyber failure 106

Figure C. 10- Failure analysis (scenario tree) for the Kingo Database cyber failure ..... 108 


\section{Introduction}

\subsection{Motivation}

Three factors motivated this research. The desire to predict cyber failures of the systems and networks of technology startups worldwide by building on recent advances made to predict cyber failures of critical infrastructures in North America was the first factor that motivated this research. Precedents for building on the knowledge gained protecting critical infrastructures to protect small businesses exist. For example, the Framework for Improving Critical Infrastructure Cybersecurity (National Institute of Standards and Technology, 2014) was developed through collaboration of the United States federal government and industry over decades. The framework organizes the processes and tools that provide the key standards and best practices that presently protect the critical infrastructures in the United States. While the framework was originally developed specifically for critical infrastructures, it has been used to develop a guide to help small businesses provide basic security for their information, systems, and networks (National Institute of Standards and Technology, 2016).

The second factor that motivated this research was the desire to fill a knowledge gap identified in the academic literature: how to predict cyber failures using an anticipatory method and publicly available information on past cyber failures. To make cyber failure predictions, most processes use secret or restrictive information. To the knowledge of the researcher and her supervisor, studies that report on the application of an anticipatory method to predict and mitigate cyber failures using publicly available 
information about resources that contributed to past cyber failures have not been published. The prevalent use of secret or restricted information to make cyber failure predictions prevents the development of online resources that maintain data on past failures of critical infrastructure and non-critical infrastructure systems at a global scale.

The third factor that motivated this research was the prospect that knowledge gained predicting cyber failures of technology startups linked by global ecosystems could be used to predict failures of critical infrastructures and a variety of non-critical infrastructures. Presently, the academic and professional literature on predicting cyber failures of critical infrastructure is better developed than the literature on predicting failures of systems and networks of technology startups and other non-critical infrastructure systems. The day may come when rapid advances in the literature on predicting cyber failures of technology startups will offer benefits to the extant literature.

\subsection{Prediction Method}

Predicting cyber failures of a system likely to or liable to suffer from cyberattacks, requires a process and information about past cyber failures (Teixeira et al., 2015). The processes used to predict cyber failures depend on methods that can be organized into traditional risk analysis methods and anticipatory methods.

Traditional risk analysis methods used to predict cyber failures of critical infrastructure include HAZOP, HAZID, fault tree, scenario tree, and event tree analysis (Ahmed et al., 2007; Dunjó et al., 2010). These traditional risk analysis methods use 
linear inductive thinking or logical modeling to answer questions such as "How did this failure happen?" or "How can this failure happen?” (Zio, 2016 a,b).

The researcher selected the Anticipatory Failure Determination (AFD) method for carrying out the research for two reasons. First, the application of the AFD to protect critical infrastructures has been gaining momentum recently. Boyes (2013), Clothier and Walker (2015), Gay and Sinha (2012), Masys (2012), and Zio (2016 a, b) suggest the use of the AFD method to predict and mitigate cyber failures in critical infrastructure.

The second reason for selecting the AFD method is because of the experience that exists using it to predict failures in manufacturing processes. The AFD method considers the information about past failures, their systems, and details of existing systems which are accessible online. Users of the AFD method identify the set of resources that contributed to a past failure - without one of the resources the failure could have not occurred (Kaplan et al., 1999; Proseanic et al., 2000; Sunday, 2014; Regazzoni and Russo, 2010).

AFD is a risk assessment method that systematically predicts and mitigates failure scenarios from a different perspective than the one used to carry out traditional failure analysis (Masys, 2012). The AFD method captures topological, functional, static and dynamic cyber failures that traditional risk analysis methods do not (GhasemiGol et al., 2016; Kröger \& Zio, 2011; Kwon and Hwang, 2016; Rawal et al., 2016). AFD uses the knowledge gained from previous failures and experiences to provide answers to questions 
such as "If I wanted to create this failure, how could I do it?" AFD addresses the means that cause a known failure to occur and the means that can cause unknown failures.

Kaplan et al. (1999) introduced the AFD method and suggested its use to examine cases of human errors, sabotage, and terrorism. AFD is based on I-TRIZ, a Russian short form of the theory of inventive problem solving (Sunday, 2014). The AFD extracts information about the resources that contributed to a failure (Masys, 2012) and mitigates occurrence of failure scenarios, by making explicit the knowledge about the failures and mitigation methods and disseminating it (Kaplan et al., 1999).

\subsection{Goal, research question and objectives}

The goal of this research is to identify the factors that enable and constrain the use of the AFD method and publicly available information on past cyber failures of critical infrastructures to predict cyber failures of technology startups.

The research question of this thesis is "how to use publicly available information about past failures in critical infrastructures to predict cyber failures of technology startups?"

The objectives of this research are:

1) Identify the components of the AFD method that can be used to predict cyber failures using publicly available information 
2) Develop an anticipatory process to predict failures of non-critical infrastructure systems using publicly available information about past cyber failures in critical infrastructures

3) Predict cyber failures in a target system of a technology startup using the anticipatory process developed

\subsection{Deliverables}

The deliverables of this research include:

1) A resource knowledge inventory - a list of the resources that were used to cause failures in critical infrastructures over the last ten years.

2) An anticipatory process to predict cyber failures of non-critical infrastructure systems that uses publicly available information about past critical infrastructures failures.

3) Predictions of failure scenarios of LTW-Start, a stack of open source software.

4) Identification of the factors that enable and constrain the use of AFD and publicly available information to predict cyber failures.

\subsection{Relevance}

This research will be relevant to the stakeholders of cyber infrastructures as well as the operators of the nodes that distribute and support LTW-Start, the system that was used to make predictions of cyber failures.

Stakeholders of cyber infrastructure include operators, suppliers, open source communities, contractors and other organizations that affect or affected by cyber infrastructures. This research is relevant to these stakeholders because it is initiating 
anticipatory thinking "to find the failures before they find us" (Kaplan et al., 1999).

Anticipating failures in cyber infrastructures enables stakeholders to take proactive action to cost-effectively mitigate them.

This research is relevant to the engineers who design systems prone to cyberattacks because it increases awareness of how a weak design and bugs in systems may have a significant adverse impact on systems and collective of systems. Deliverables assist to predict failures autonomously from individual experience and knowledge, by transmitting the most recent worldwide experience about failures in critical infrastructures and noncritical systems that is publicly available.

This research is relevant to government policy makers because it provides a process to use publicly available information to predict and invent potential failures in different systems which can help shape future standards and policies for the purpose of mitigating the risk of future cyber failures.

The production and dissemination of an inventory of resources that contributed to the past failures of critical infrastructure around the world can raise awareness of cyber threats and increases capability to anticipate future failures.

The organizations that are part of the GCR network and open sources communities will find this research relevant. These node operators and open source communities are developing a fusion centre to mitigate cyber failures of LTW-Start. 


\subsection{Contribution}

The main academic contribution of this research is to fill a knowledge gap identified in the literature- How to predict failures using the AFD and publicly available information about past failures in critical infrastructures.

This research makes at least two contributions to practitioners. First, the research

helps young engineers have a broader view of security concerns when designing systems that are prone to cyber attacks. Young engineers can use the resource knowledge inventory rather than rely on just their knowledge gained from education and personal experiences. Since "the human" is still recognized as the weakest link in a security chain (Katz et al., 2016), the use of a resource knowledge inventory will enhance their understanding of potential failures in systems and may help them to take proactive actions to mitigate risks of cyber failures.

The second contribution this research makes to practitioners is that it demonstrates how to use a resource knowledge inventory to predict failure scenarios of a specific target system.

\subsection{Organization}

Chapter 2 provides a review of the literature. Chapter 3 describes the method used to carry out this research. Chapter 4 outlines the results of the study. Chapter 5 provides a 
discussion of the results. Finally, Chapter 6 provides conclusions, identifies the limitations of the research and makes recommendations for future work. 


\section{Literature review}

\subsection{Background}

Integration of smart devices into the traditional topology of industrial infrastructure has evolved it to relatively smart systems. This, enhanced the quality of monitoring and controlling systems on the one hand and becomes an Achilles' heel of the system from security point of view.

The number of cyber failures in critical infrastructures continues to increase (McAfee, 2015). Potential catastrophic consequences from these failures is a major concern (Katz et al., 2016; Wang \& Lu, 2013; Kalogridis et al., 2014; Tweed, 2014; Zio, $2016 \mathrm{a}, \mathrm{b})$. The United States has considered this paramount by issuing versions of North American Electric Reliability Corporation's Critical Infrastructure Protection (NERC CIP) regulations. The National Institute for Standards and Technology (NIST) framework for protection of critical infrastructure cybersecurity, Canada's Action Plan for Critical Infrastructure, and European Critical Infrastructure Warning Information Network are just a few number of several governmental policies to investigate cybersecurity threats to critical infrastructure (Katz et al., 2016).

Installing smart devices without robust security protections resulted in a hybrid structure in current industrial sites and critical infrastructures causing vulnerabilities in Industrial Control Systems (ICS) and cybersecurity challenges such as stealing or injecting data for malicious goals or controlling components by unauthorized access or 
even by physical access to remote compartments that were not protected properly (Katz et al., 2016).

Operating system of embedded computing devices have less protection than serverlevel computers due to lack of proper software stacks, logging, and audit in TCP/IP (Transmission Control Protocol/ Internet Protocol). These components are used in several smart devices such as smart meters, relays, and substation control systems but simplified in order to limiting hardware requirement or reliability. Recently, cybersecurity policy makers enforce development of protection guards for these devices by protocols and regulations (Katz et al., 2016).

\subsection{Failure anticipation in critical infrastructure}

Industrial systems are vulnerable to cyber breach by 96 percent in average. Continuously new attackers with new skill sets are joining to the battle to find a vulnerability to cause a cyber failure. Dark webs were developed for sharing the knowledge and complementing professional attackers. On the other hand, stakeholders of critical infrastructures need to secure the systems, operations, human interactions and dynamic information management. This warfare requires anticipating strategies to take first move advantage (Rawal et al.,2016).

Although future failures anticipation is challenging for stakeholders of complex systems, some information about potential failures in a system can improve decision making in present. Attack graph is the most common method of risk analysis and failure 
prediction, while it only provides static information about potential failure (GhasemiGol et al.,2016).

Traditional failure analysis methods such as HAZOP, HazID, fault tree, and event tree analysis are investigating the systems to find what can go wrong. While, these methods are based on linear inductive thinking and are not able address topological, behavioral, and dynamic aspects of systems. Increasing number of "surprise events" indicates that different perspectives than traditional ways are required to investigate potential failures in systems (Zio, 2016 a).

Other techniques such as Red Team analysis techniques and penetration test are being used to discover vulnerabilities of a system under study by asking attackers to break into system under controlled condition (Loewengart, 2012). While, Red Team Journal in several articles indicated that the outcome of this attack maneuver significantly depends on the quality and experience of red team, the team's approach and toolset, and the overall context of attempt. It is stated that culturally biased and overconfident team will not help the systems' security.

Statistics shows that system-level breakdowns were initially caused by small distresses with cascading consequences. Predicting cyber failures in complex systems encounters barriers to address behavioral, functional, topological and human interaction vulnerabilities (Zio, 2016), while human is stated to be the most vulnerable factor in 
cybersecurity that need impact measurement, security programs, training, and authority limitations (Katz et al., 2016).

Recently, different scholars suggested to use Anticipatory Failure Determination (AFD) method for proactive cybersecurity in the systems (Boyes, 2013; Clothier and Walker, 2015; Gay and Sinha, 2012; Masys, 2012; Zio, 2016 a, b). Application of AFD has been studied during this research to find factors that enable and constrain the use AFD in cyber domain.

\subsection{Anticipation theory}

Robert Rosen (1985) defines anticipatory system as "A system that contains a predictive model of itself and/or its environment, which allows it to change state at an instant in accord with the model's predictions pertaining to a latter instant".

If we consider system $\mathrm{S}$, as interest system, and model it in $\mathrm{M}$ in such a way that $\mathrm{S}$ is parametrized in real-time and $\mathrm{M}$ parametrized by time variable which is quicker than real-time. We can predict behavior of $\mathrm{S}$ from behavior of $\mathrm{M}$ at specific time t. Interaction between $\mathrm{M}$ and $\mathrm{S}$ through a set of effector $\mathrm{E}$, which change the dynamical properties of $\mathrm{S}$ and enables $\mathrm{M}$ to influence $\mathrm{S}$ directly or by changing environmental inputs.

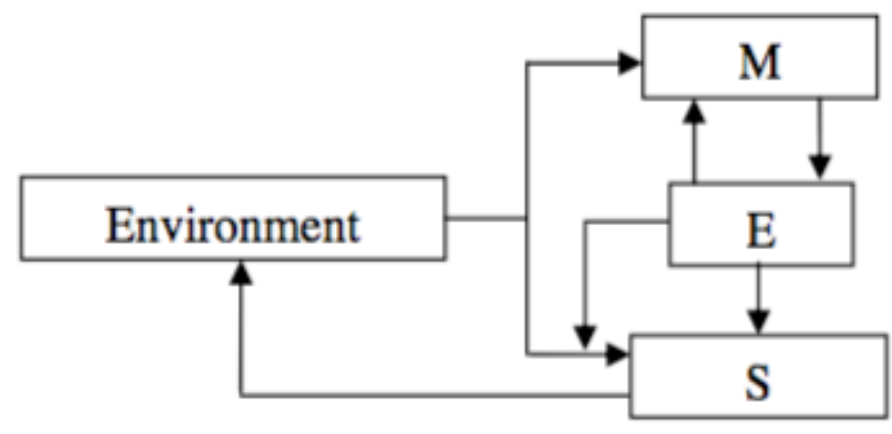


Anticipatory system according to Rosen's approach is adaptive system which defines current state based on predictions about future (Kohout, 2011).

\subsection{Anticipatory failure determination method}

Anticipatory Failure Determination (AFD) introduced by Kaplan et al. (1999) is an application of an advance form of Russian-developed Theory of Inventive Problem Solving (I-TRIZ) namely Scenario Structuring which is a subset of Risk Analysis AFD is based on principles that employ traditional RA methods to develop future failure scenarios that called Theory of Scenario Structuring.

The AFD method accumulates and organizes the worldwide experience in the operation and design of various systems, to make this knowledge available to new designers, in such a way that the mistakes, accidents and oversights of the past, provide insight for engineering activities and culture in future (Kaplan et al., 1999).

Kaplan et al. (1999), Proseanic et al. (2000), Sunday (2014), and Regazzoni and Russo (2010) are the literatures that used AFD method to solve problems in manufacturing and process development while to the knowledge of this research no literature has used the AFD to predict cyber failures using publicly available information about the past cyber failures in critical infrastructure. 
To develop scenarios, the principles defined by Kaplan et al. (1999) as follows:

\subsubsection{Principles of scenario structuring}

1) The principle of $\mathrm{S} 0$

$\mathrm{S} 0$ is the "success" scenario or "as-planned" scenario which clearly defines what that system or activity designed for.

2) The principle of initiation $(\mathrm{Si})$

A failure scenario from as-planned scenario ( $\mathrm{S} 0$ ), must have point of departure-a point at which something causes different consequence from expectations, which called Initiating Failure or Initiating Event (IE).

3) The principle of emanation

Each IE could be initiation of different scenarios depend on latter situations which is the way scenario tree are developed. Each path through the tree represent specific scenario and continues until reaches the "end" of scenario, called end state.

4) The principle of unending cause-effect

Every cause-effect chain is extendable in both directions since each happening has its own consequences and initiations.

5) The principle of subdivision

Every scenario could be extended to different new scenarios in more details.

6) Pinch Point Principle

Scenario tree may have pinch points, independent of upstream path leads to those points. These point are also called middle state. (MS) 
7) Fault and event trees

There are variety sets of probable failure scenario for any real-world situation and managing and organizing these scenarios in order to identify most and least critical ones and define priorities is the main challenge.

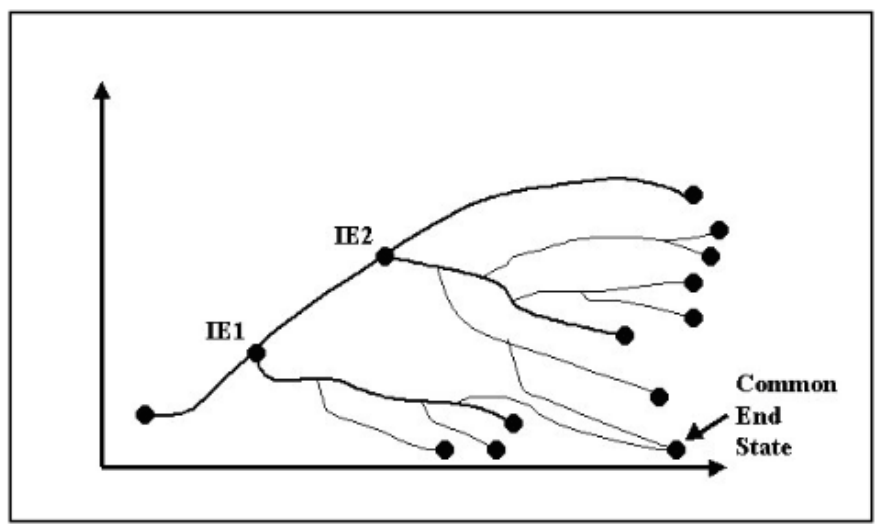

Figure 2-Branches from two different trees can end at the same end state (Kaplan et al.,1999)

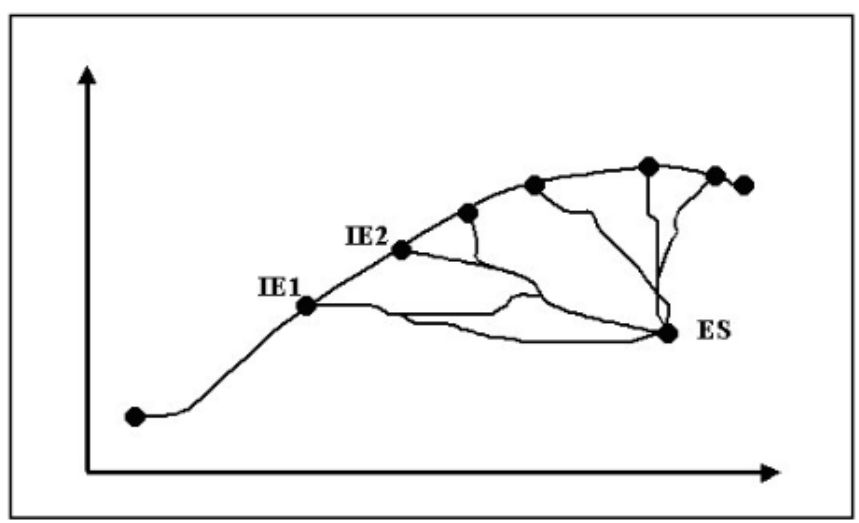

Figure 3-Incoming scenario tree(Kaplan et al.,1999) 


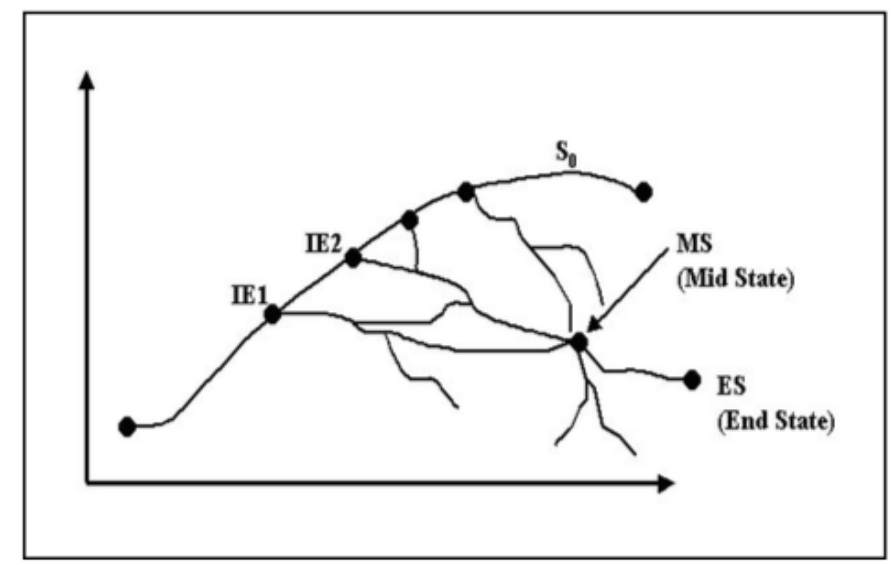

Figure 4-"mixed" Scenario tree(Kaplan et al.,1999)

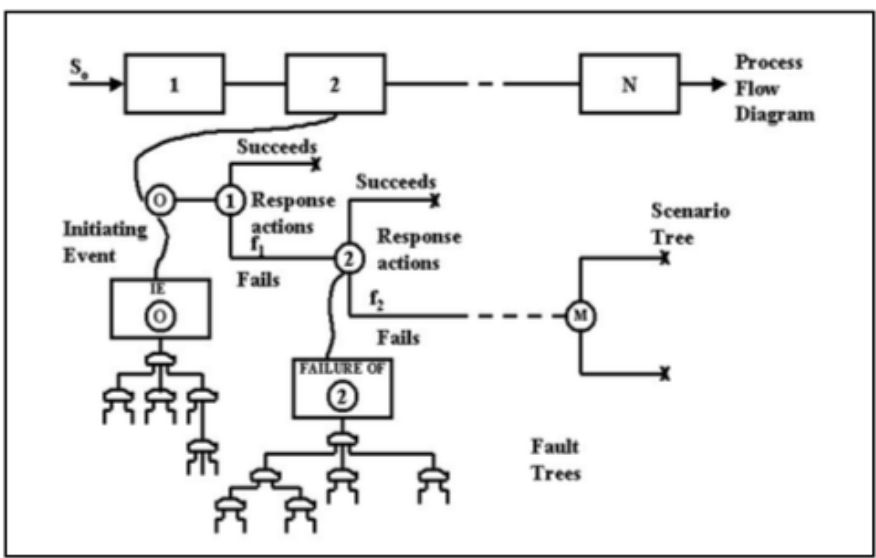

Figure 5-Combined Use of Forward and Backward Trees(Kaplan et al.,1999)

8) The principle of resources

All the configurations, time, space, fields and other factors engaged in specific event are called resources. Based on this definition all of the resources should be available in order to have that event been happened and without even one of the resources the failure will not happen.

\subsubsection{Scenario structuring using fault and event trees}

Scenario Structuring suggested by Kaplan et al. (1999) develops event trees in three ways: 
1) Find the possible IEs and draw the outgoing trees from each

2) Find the important ESs and draw the incoming trees to each

3) Find important mid-states and draw the incoming /outgoing trees to each

\subsubsection{AFD Applications: Failure Analysis (AFD-1) and Failure Prediction (AFD-2)}

Differentiation of AFD with other methods of failure anticipation is to invent failures by changing attitude toward failure. Instead of learning from past failures to prevent them in future, AFD looks for failures that has not happened before. Indeed, instead of asking "What can go wrong in my system?" AFD asks "How can I make things go wrong in the most effective way?" as well as asking "How can I create the particular (proposed) failure?". Once the failure methods identified they can be prevented or limited. All the required conditions and criteria for failure occurrence called resources.

AFD is constitute of two processes of Failure Analysis (AFD-1) and Failure Prediction (AFD-2). AFD-1 finds the roots of the failure that has already happened using RA methods mentioned in 2.2. AFD-2 predicts all the possibilities to predicts new failures using knowledge inventory accumulated from several AFD-1 cycles. AFD-2 application will result in creative solutions to cause failure and predict scenarios that have not happened before.

\subsubsection{AFD-1: Failure Analysis}

The structure of "thought process" in AFD-1 is stated as:

Step 1: Formulate the original problem including naming the system, its purpose and failure situation

Step 2: Identify the success scenario: phases of operation, intended results in each phase 
Step 3: Localize the failure to reduce the area of analyze by identifying the last event that during which or right after which the failure happened.

Step 4: Formulate and amplify the inverted problem by changing the attitude to create observed failure.

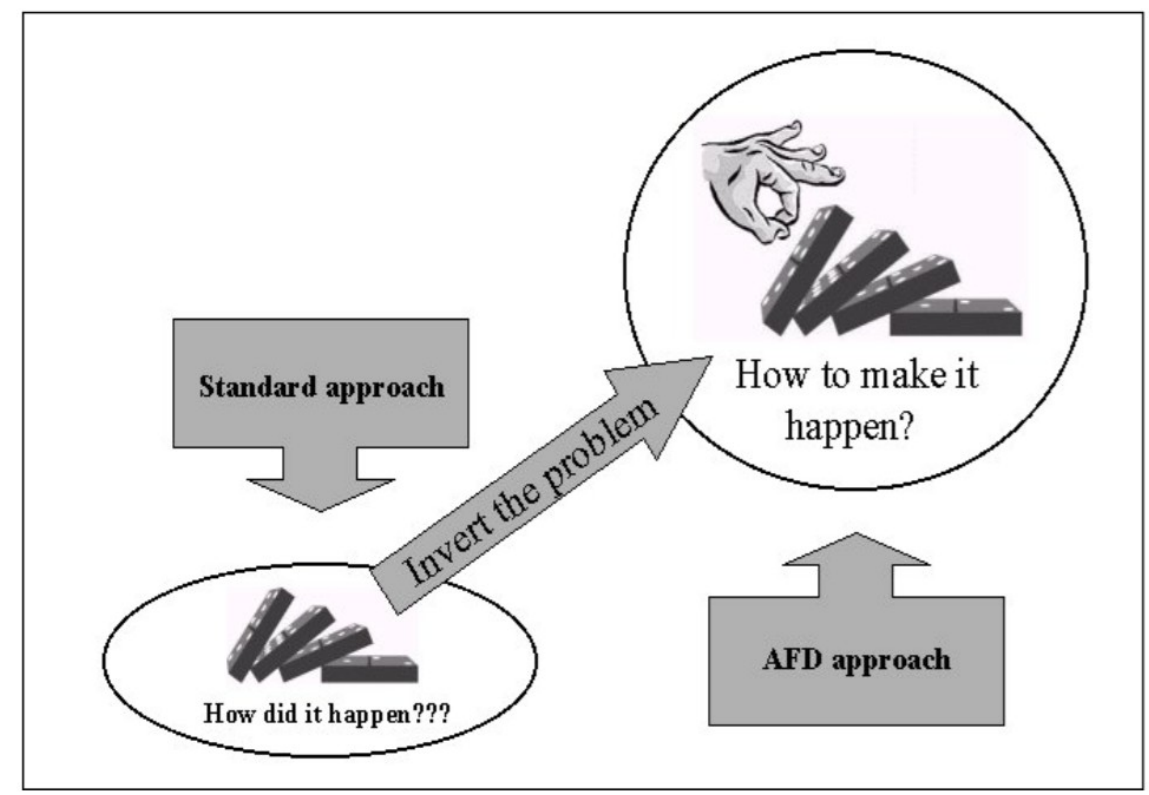

Figure 6-Inverting the Problem(Kaplan et al., 1999)

Step 5: Search for solutions to cause identified failure. This is the area that research, patents, and experience come to practice to search for standard and obvious solutions, identifying resources such as required substances, fields, spaces, time, information, functions. 


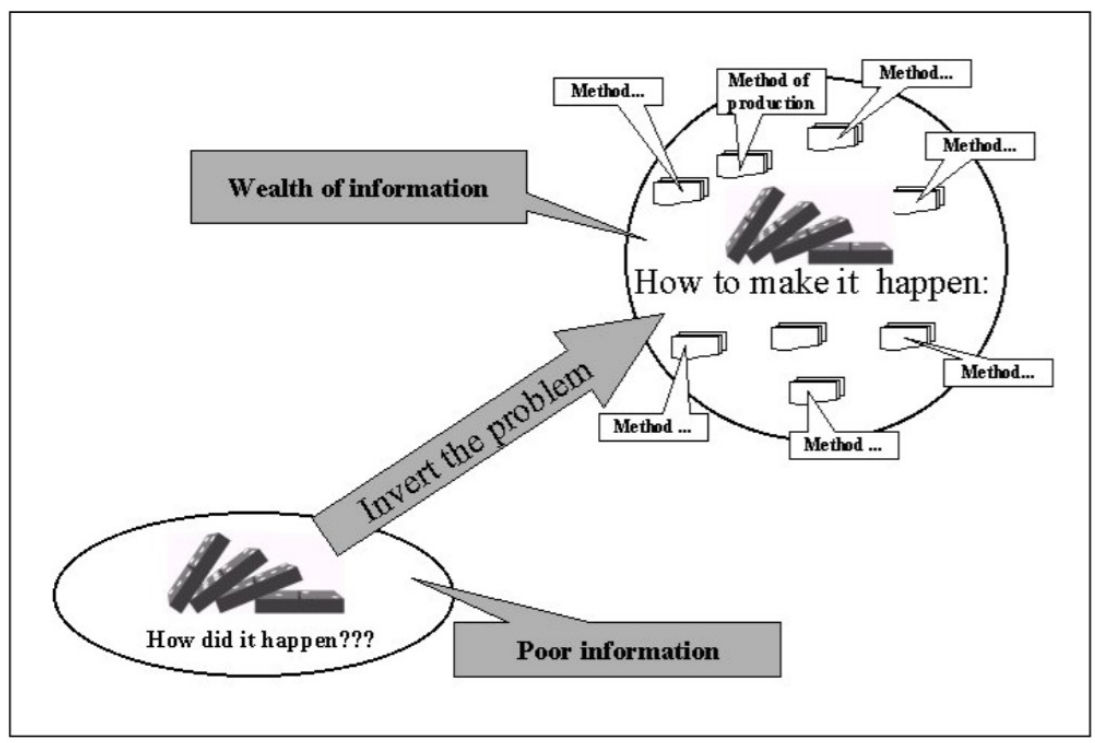

Figure 7- Inverting problem from "How does it happen?" to "How can it be produced?" (Kaplan et al., 1999)

Step 6: Formulate hypotheses and design test to verify them by comparing "what is needed "to create specific failure, and "what exist" leads us to develop different hypotheses.

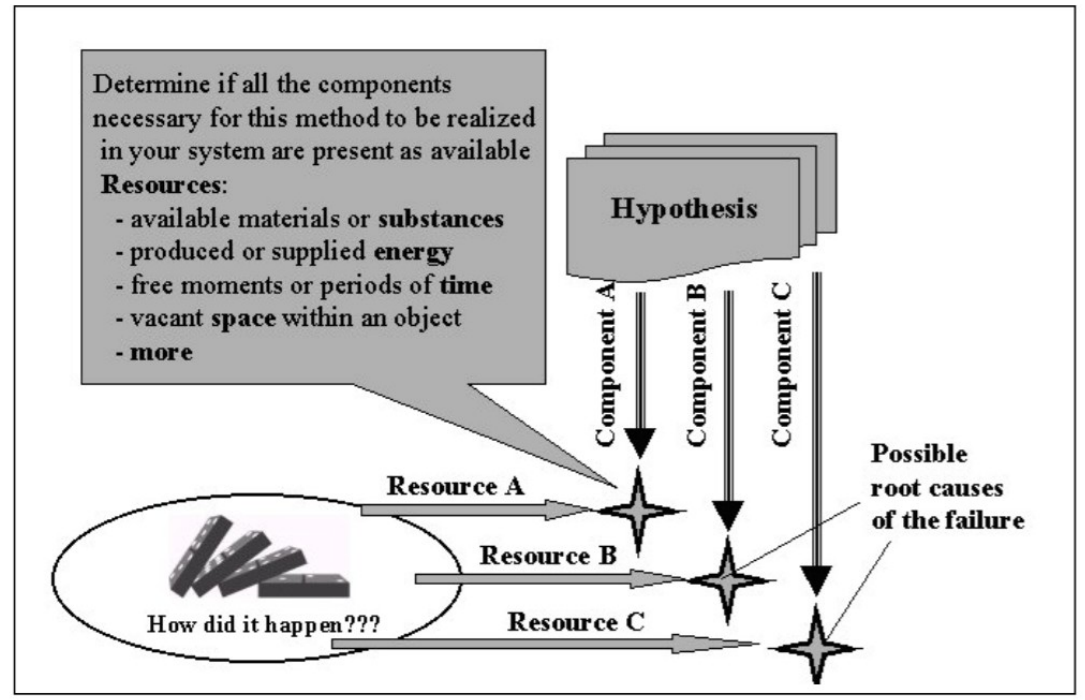

Figure 8- Utilization of resources(Kaplan et al., 1999)

Step 7: Correct the failure which is the last step to find preventive ways of failures. 
Templates to develop AFD-1 retrieved from Kaplan et al. (1999) included in Appendix

A.

\subsubsection{AFD-2: Failure prediction}

Failure prediction process is very similar to failure analysis; the only difference is that failure prediction looks for "all" or at least "all of the important " failures that can happen to system which results in IEs, MSs, HESs, and $S_{i} s$.

Step 1: Formulation of all (or all the important) possible failures

Step 2: Defining success scenario, $\mathrm{S}_{0}$, phases of process , and results in each phase.

Step 3: Formulate the inverted problems

Step 4: Find all possible failures of a system by considering IEs, HESs, and MSs

individually, then, developing integrated scenario tree by combining them.

Step 5: Survey to find available resources which may cause failures in our system, while they were not considered before. These potential failure scenarios should be added to integrated tree as well.

Step 6: Utilize accumulated knowledge

Step 7: Invent new solutions

Templates to develop AFD-2 retrieved from Kaplan et al. (1999) included in Appendix B.

\subsection{Constructive research}

The constructive research is used to find solution such as processes, practices, tools or organizational charts for practical problems by employing academic theoretical perspectives. The research process involves following steps (Lehtiranta, 2015): 
1) Selecting a practically relevant problem

2) Obtaining a comprehensive understanding of the study area

3) Designing one or more applicable solutions to the problem

4) Demonstrating the solution's feasibility

5) Linking the results back to the theory and demonstrating their practical contribution

6) Examining the generalizability of the results

The examples of constructive research approaches are Chen (2002), Pellerin (2003), and Bhuiyan et al. (2004). In this research A process developed to solve the problem of predicting future cyber failures using publicly available information.

\subsubsection{Theory building assessment}

Arend et al. (2015) proposed an inclusive theory-assessment framework based on outstanding works of past scholars (i.e. Bacharach, 1989; Boxenbaum and Rouleau, 2011; Dubin, 1969; Eisenhardt, 1989; Gioia and Pitre, 1990; McKelvey, 1997; Mohr, 1982; Priem and Butler, 2001; Suddaby, 2010; Sutton and Staw, 1995; Thomas and Tymon, 1982; Whetten, 1989). It defined the applicable criteria objectively in the form of a table. The application of the table evaluates the theory and leads to possible future development to enhance the theory building (Arend et al., 2015).

Three stages of assessment include assessing 1) Experience: capture the focal phenomenon both academically and practically, 2) Explain: build theory that describes mechanics, 3) Establish: Empirically and critically, diffusion, value in the field. Table 1 demonstrates theory-building criteria and assessment developed by Arend et al. (2015) 


\begin{tabular}{|c|c|c|}
\hline Stage & Criteria & Recommendations \\
\hline \multirow[t]{2}{*}{ Experience } & Build on existing theory & Reference to existing work \\
\hline & Build on valid observations & $\begin{array}{l}\text { Number of observations, observers' } \\
\text { expertise }\end{array}$ \\
\hline \multirow[t]{8}{*}{ Explain } & $\begin{array}{l}\text { Units: comprehensive, } \\
\text { parsimonious }\end{array}$ & Units are well defined \\
\hline & Clear laws for units' interactions & Directionality, relationships \\
\hline & Precise boundary laws & $\begin{array}{l}\text { Specify focal dependent variables, } \\
\text { sequences, outcomes, etc. }\end{array}$ \\
\hline & System state exists & At least one state \\
\hline & $\begin{array}{l}\text { Propositions consistent with } \\
\text { model }\end{array}$ & All three types: fact, value, and policy \\
\hline & Reasonable assumptions & Clarify flows, bounded rationality \\
\hline & $\begin{array}{l}\text { Logical: explicit causality, no } \\
\text { tautologies }\end{array}$ & $\begin{array}{l}\text { Explain causality for main laws; } \\
\text { delineate what is not true, split if not } \\
\text { coherent }\end{array}$ \\
\hline & Coherent & $\begin{array}{l}\text { Fit among ontology, epistemology, } \\
\text { methodology, human nature } \\
\text { assumptions }\end{array}$ \\
\hline \multirow[t]{3}{*}{ Establish } & Empirically testable & Falsifiable predictions are provide \\
\hline & Diffused in literature & Number of people engaged is large \\
\hline & $\begin{array}{l}\text { Practitioners value: } \\
\text { understandable, nonobvious, and } \\
\text { implementable }\end{array}$ & $\begin{array}{l}\text { Ideas written in straightforward way; } \\
\text { concepts are field ready; constraints } \\
\text { are absorbed into process in the field }\end{array}$ \\
\hline
\end{tabular}

Table 1- Theory-building criteria and assessment developed by Arend et al. (2015)

\subsection{Resources and resource classification}

Literature review demonstrates different criteria to define resources. Kaplan et al. (1999) defined resources the all configurations, substances, time, space, fields, information, functions and other factors engaged in specific event. Christensen and Kaufman (2006) defined resources as people, equipment, technology, product, brands, information, cash and relationships with suppliers, distributors, and customers.

Resources are things that can be hired and fired, bought and sold, depreciated or built. Most resources are visible and often are measurable, so managers can know what they have. Resources tend to be 
flexible as well: most can be transported across organizational boundaries. An engineer who is a valuable contributor in a large firm can quickly become a valuable contributor in a start-up. Technology developed for telecommunications can be valuable in health care. (Christensen and Kaufman, 2006)

Langley et al. (2013) suggested to address the ontology of resources in process research, while, different ontologies are defined for resources in the cyber world. Van Heerden et al. (2012) defined the ontology of resources as: Actors, actor location, aggressor, attack goal, attack goal, attack mechanism, automation level, effects, motivations, phases, scopes, targets, vulnerabilities. Syed et al. (2016) defined a unified cybersecurity ontology (UCO) the means, consequences, attack, attacker, attack pattern, exploit, exploit target, and indicators. Undercoffer et al. (2004) defined an ontology for computer attacks which includes target, attack strategy, attacker location and end results (Van Heerden et al., 2012).

Van Heerden et al. (2012) stated that high-quality taxonomy is required to be acceptable, comprehensive, complete, determined, excusive, repeatable, constant and solidly defined, unambiguous and useful (Hansman, 2003). The taxonomy provided by Van Heerden et al. (2012) mainly complies usefulness, mutual exclusivity, comprehensibility and unambiguity, while it is emphasized that broad scope of network attack confines adherence to other requirements (Van Heerden et al., 2012).

Van Heerden et al. (2012) provided subdivision for different classes of taxonomy based on comprehensive literature review to define a basis for ontology as follows: 
1) Actor: Commercial competitor, hacker, insider, organized criminal group, protest group

2) Actor location: Foreign actor location, local actor location, intermediate actor location

3) Aggressor: Individual, commercial, state, group

4) Attack goal: Change data, destroy data, disrupt data, steal data, springboard for other attack goals

5) Attack mechanism: Access: brute force, buffer overflow, spear phishing, physical; data manipulation: network-based (i.e. denial of service); Virusbased; Trojan, virus, worm; web application-base: SQL injection, cross-site scripting (XSS); information gathering: scanning, physical

6) Automation level: Manual, automatic, semi-automatic

7) Effects: Null, minor damage, major damage, catastrophic

8) Motivation: Financial, fun, ethical, criminal

9) Phase: Target identification, reconnaissance, attack phase: ramp-up, damage, residue; post-attack reconnaissance

10) Scope: Corporate network, government network, private network

11) Target: Personal computers, network infrastructure device, server 
12) Vulnerability: Configurations: Access rights, default setup; design: open access, protocol error; implementation: buffer overflow, race condition, SQL injection, variable type checking

Noy and McGuinness (2001) expressed ontology “a common vocabulary for researchers who need to share information in a domain "while due to newness of the domain and the broad applications still solid ontology has not been accepted to share the information of the cyber domain. 


\section{Method}

Chapter 3 describes the method used to carry out the research. Section 3.1 describes the motivation, research question, objectives, and the approach used to carry out the research. Section 3.2 describes the research method and Section 3.3 provides the summary of this chapter.

\subsection{Motivation, research question, objectives, and the approach}

\subsubsection{Motivation}

The primary motivation of this study is to identify the enablers and constraints to use AFD method to predict failures using publicly available information of past failures in critical infrastructure.

\subsubsection{Research question and objectives}

The research question of this thesis is "how to use publicly available information about past failures in critical infrastructures to predict cyber failures of technology startups?”

The objectives of this research are:

1) Identify the components of the AFD method that can be used to predict cyber failures using publicly available information

2) Develop an anticipatory process to predict failures of non-critical infrastructure systems using publicly available information about past cyber failures in critical infrastructures 
3) Predict cyber failures in a target system of a technology startup using the anticipatory process developed

\subsubsection{Approach}

This research used the constructive approach (Lehtiranta et al., 2015) similar to the research that were done by Chen (2002), Pellerin (2003), and Bhuiyan et al. (2004). First, the drafts of the process and the resources knowledge inventory were developed as prototypes. Then, the drafts were reviewed by three experts (Arend et al., 2015). The feedbacks from the experts were incorporated in final version of the process and the resource knowledge inventory. Final versions of prototypes were used in a sample system in latter stages.

\subsection{Research method}

Table 2 identifies the steps carried out in this research. 


\begin{tabular}{|c|c|c|}
\hline Step & Activity & Outcome \\
\hline 1 & $\begin{array}{l}\text { Literature review in five streams } \\
\text { including cyberattacks } \\
\text { anticipation in critical } \\
\text { infrastructure, failure analysis } \\
\text { methods, anticipation, } \\
\text { constructive approach, and } \\
\text { classification in cybersecurity }\end{array}$ & $\begin{array}{l}\text { Knowledge gap and set of lessons } \\
\text { learned }\end{array}$ \\
\hline 2 & $\begin{array}{l}\text { Define the process to transform } \\
\text { publicly available information } \\
\text { about cyber failures in critical } \\
\text { infrastructures into predictions of } \\
\text { future failures }\end{array}$ & $\begin{array}{l}\text { A process that uses an anticipatory } \\
\text { method and publicly available } \\
\text { information to predict failures }\end{array}$ \\
\hline 3 & $\begin{array}{l}\text { Produce descriptions of past cyber } \\
\text { failures using publicly available } \\
\text { information }\end{array}$ & Descriptions of cyber failures \\
\hline 4 & $\begin{array}{l}\text { Develop a draft of a resource } \\
\text { knowledge inventory using the } \\
\text { process developed in step } 2 \text { to } \\
\text { examine the descriptions of the } \\
\text { cyber failures produced in step } 3\end{array}$ & $\begin{array}{l}\text { Draft of a resources knowledge } \\
\text { inventory - an inventory of resources that } \\
\text { indicated or contributed to past cyber } \\
\text { failures in critical infrastructures }\end{array}$ \\
\hline 5 & $\begin{array}{l}\text { Incorporate feedback about the } \\
\text { process used to examine } \\
\text { descriptions of cyber failures and } \\
\text { the resource knowledge inventory } \\
\text { produced from three experts }\end{array}$ & $\begin{array}{l}\text { Revised process and revised resource } \\
\text { knowledge inventory using experts' } \\
\text { feedback }\end{array}$ \\
\hline 6 & $\begin{array}{l}\text { Use the revised version of the } \\
\text { process produced to predict } \\
\text { potential failure scenarios in a } \\
\text { system }\end{array}$ & $\begin{array}{l}\text { Potential resources that may cause } \\
\text { failure, and failure scenarios }\end{array}$ \\
\hline 7 & $\begin{array}{l}\text { Identify the factors that enable } \\
\text { and constrain the use of the AFD } \\
\text { method to predict cyber failures } \\
\text { using publicly available } \\
\text { information }\end{array}$ & $\begin{array}{l}\text { Enablers and constraints of using AFD } \\
\text { method to predict cyber failures using } \\
\text { publicly available information }\end{array}$ \\
\hline
\end{tabular}

Table 2-Research Method

\subsubsection{Lessons learned and knowledge gap}

Literature review initially conducted in two streams of cyberattack anticipation in critical infrastructure and anticipation theory. The combination of key words such as "critical infrastructure", "anticipation" or "anticipatory", "prediction" or "predict", and 
"cybersecurity" were searched using Google and Google Scholar tools to find related literature published since 2012. Later, three other literature streams, including failure analysis methods, classification in cybersecurity, and constructive theory, were reviewed due to research requirements.

The increasing number of "surprise events" that negatively affect critical infrastructures indicates the need for anticipatory methods that predict and mitigate potential failures from different perspectives. Anticipatory methods that start from a proposed future failure and use deductive methods to investigate the bugs and interconnections that can lead to the failure in the system, provide insight about failure circumstances (Zio, 2016 a).

The AFD method introduced by Kaplan et al. (1999) anticipates failure scenarios as a "creative act" with a comprehensive detailed plan to identify all the resources that are needed for occurrence of a failure in the system (Zio, $2016 \mathrm{a}, \mathrm{b})$. The strength of AFD is intentionally "inventing" the failure events and scenarios using the knowledge inventory. By asking” If I wanted to create this failure, how could I do it?”.

AFD is comprised of failure analysis (AFD-1) and failure prediction (AFD-2). AFD-1 uses traditional risk analysis methods to identify the resources that enabled failures in the past. AFD-2 uses results of several AFD-1 iterations to find all the possible resources that may lead to a failure in the system to anticipate future failures. AFD-2 
invents new failure scenarios from the existing resources in the system and defines what is needed for the specific failure to occur.

The literature includes studies of the application of AFD to protect manufacturing processes (Kaplan et al., 1999; Proseanic et al., 2000; Sunday, 2014; Regazzoni and Russo, 2010). The literature, however, does not include studies that report on the application of AFD to predict cyber failures using publicly available information about resources that contributed to the past cyber failures in critical infrastructure.

A cyber failure is a violation of a cybersecurity policy that may result in not being able to fulfill a success scenario - the results that are intended to be accomplished at a given phase (Kaplan et al., 1999).

Critical infrastructure refers to the "processes, systems, facilities, technologies, networks, assets and services essential to the health, safety, security or economic wellbeing of Canadians and effective functioning of government" (Public Safety Canada, 2015). Today, critical infrastructure combines the intelligent infrastructure with computerized control systems and it is at the core of energy transmission and distribution networks, the telecommunication networks, the transportation systems, and water and gas distribution systems (Zio, 2016 a, b).

\subsubsection{A process that uses anticipatory method and publicly available information about past cyber failures in critical infrastructures}


Figure 9 illustrates the steps of AFD-1 and AFD-2 as described in Kaplan et al.

(1999). AFD-1 uses traditional risk analysis methods to identify all resources that enabled failures in the past, in such a way that without any of the resources the failure cannot be accomplished. AFD-1 organizes the resources in a systematic inventory of resources to facilitate communication.

At the core of the AFD method is the use of private information from several past system failures to produce a resources knowledge inventory and the use of this inventory to predict system failures for the purpose of proactively mitigating them.

AFD-1: Failure analysis

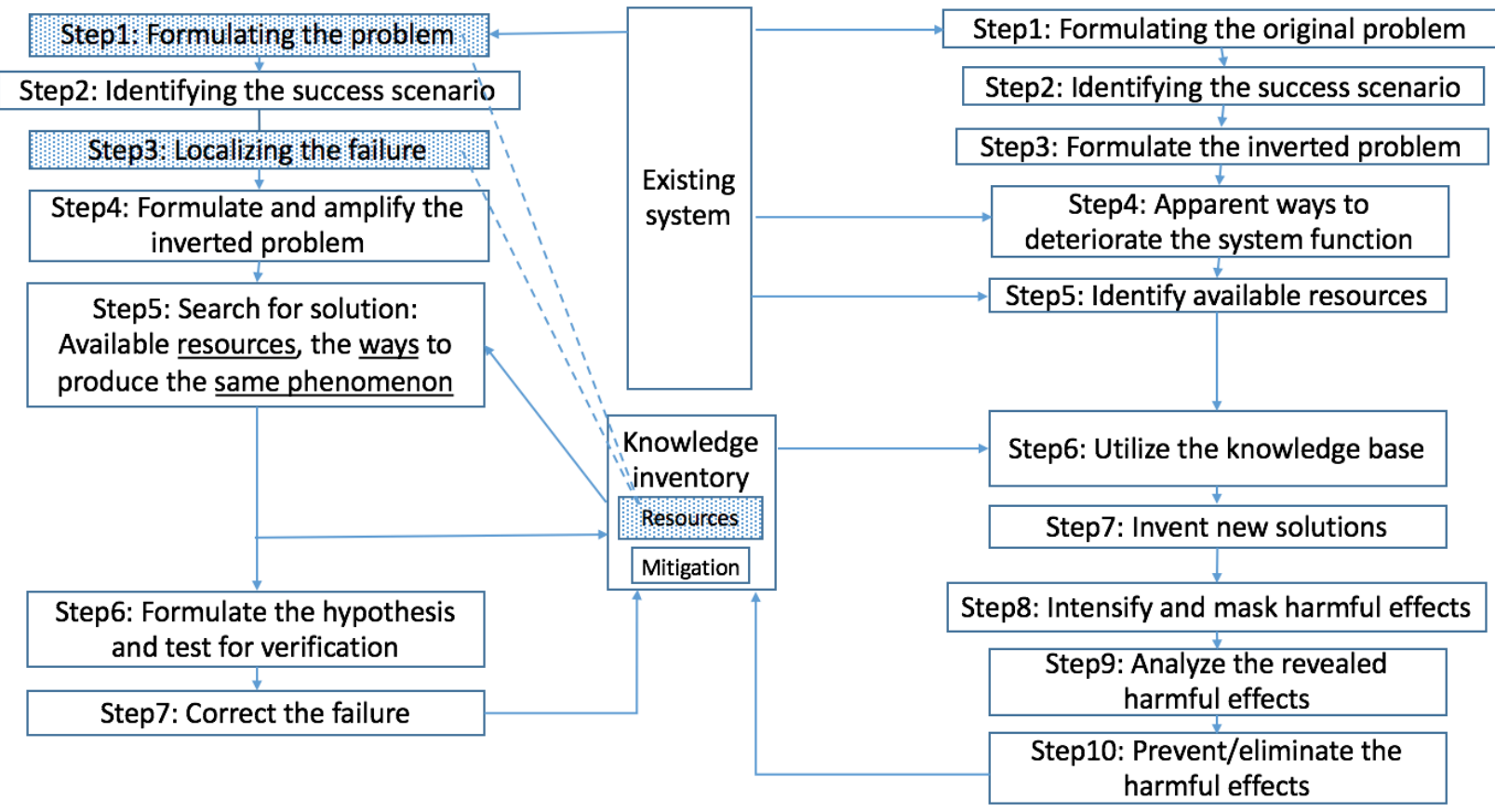

Figure 9-AFD schematic to identify the steps that can be carried out using publicly available information 
This research develops a process to transform publicly available information about past cyber failures of critical infrastructure to predict failures of a target system. The process used in this research modifies the elements of AFD-1 and AFD- 2 by selecting the steps that can be accomplished using only publicly available information from past cyber failures in critical infrastructures. Since the detail of the systems' design, architecture, and mitigation methods are either confidential or underdevelopment they were not included in the new process.

Figure 10 illustrates the process used in this research to predict failures. This process adapts the failure analysis concept of the AFD-1 and ten cyber failure descriptions extracted from publicly available information to produce a draft of a resource knowledge inventory. The inventory identifies and classifies the resources that contributed or indicated the ten failures. The final version of the resource knowledge inventory can be used to invent potential failures in step 6 of the AFD-2. 


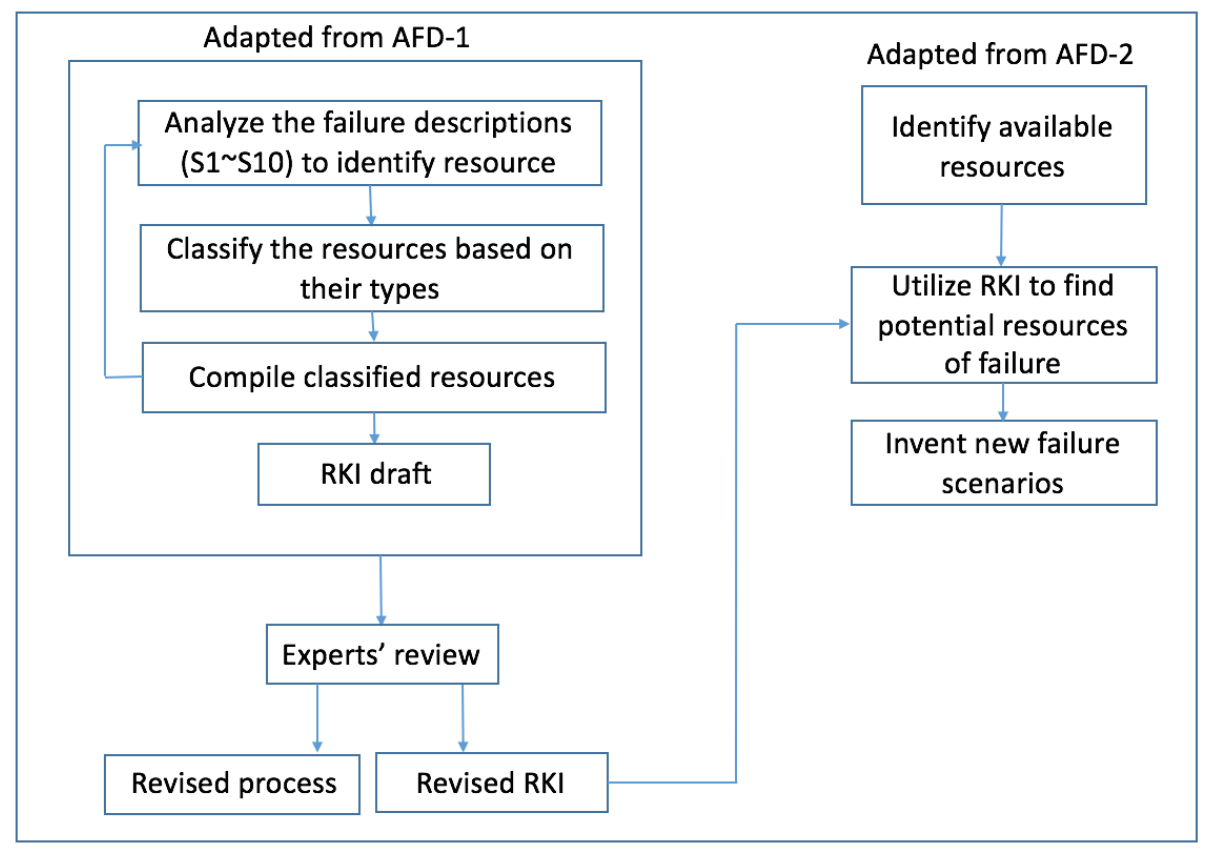

Figure 10-The process used in this research to predict failures

\subsubsection{Descriptions of cyber failures}

Cyber failures were searched according to following criteria and the selected cyber failures were consulted with a cybersecurity expert to validate the sample.

\subsubsection{Selection criteria}

The selection criteria to develop description for cyber failures in critical infrastructure occurred within last ten years were:

1. Cyber failure in critical infrastructure was an event that English speaking media outlets in North America considered to be newsworthy information

2. Reputable sources provided the information required to describe the cyber failures

3. Five or more resources were identified as being used to cause each cyber failure 
4. The supervisor of the thesis deemed the combinations of resources that caused the cyber failures to be of high-diversity

The first criterion required each cyber failure that was included in the sample to meet media outlets criteria for publication according to media college website. The editors of media outlets consider five factors when deciding if a story is newsworthy: timing (e.g., topic is current), significance (e.g., number of people affected is large), proximity (e.g., closeness to home), prominence (e.g., well known organizations and individuals were affected), and human interest (e.g., story appeals to human emotion).

The second criterion required that the sources of information used to describe cyber security failures were reliable. The following sources of information were deemed to be reliable:

1) Articles, books or research papers examined and reviewed by academics

2) Well recognized news organizations such as $\mathrm{CNN}$, BBC, Washington Post, New York Times, Bloomberg, ZDNet, Euractiv.

3) Security reports published by companies that are well-known in cyberspace such as McAfee, Symantec, IBM and Kaspersky

4) Reputable magazines such as Times

The third criterion required that the description included at least five resources about technical details or human errors that indicated or contributed to the cyber-failure. Since the purpose of developing cyber failure descriptions is to produce a resource 
knowledge inventory, the cyber failures that have at least five disclosed resources, in publicly available information, were considered in this research.

The fourth criterion required that the sample be of high diversity to enrich the resource knowledge inventory with diverse methods of failure for future applications. Since the resource knowledge inventory will be used as a reference for potential failure resources, the diversity provides broader options to invent failures which eventually can lead to the more robust systems.

\subsubsection{Search process used to find the cyber failures}

The researcher entered various combinations of keywords including "cyberattack", "security breach", "critical infrastructure", "SCADA", "ICS", "failure" into the Google, Google Scholar search utilities as well as journal databases of Carleton University library to find information on cyber failures published by reliable public sources of information.

The keywords extracted from reliable literatures, were used by Google search engine in several iterations to find more information about the cyber failure. The information about each cyber failure that met all the criteria was included in sample. These descriptions included the hypothesized and simulated failures in ICS (Industrial Control Systems) as well as SCADA (Supervisory Control and Data Acquisition) since they are known academic ways to cause failure, even though they were not representing actual failures in critical infrastructure. 


\subsubsection{Draft of resource knowledge inventory}

Developing resource knowledge inventory helps to identify the combination of resources that frequently contributed to different cyber failures to provides insight about knowing what to expect in the case we identify a resource of failure in our system. Knowing what to expect can increase the potential to identify and mitigate cyber failures.

Comparing the scenarios helped to find similar resources that can be substituted in different systems such as the set of resources contributed to breach the network in different systems. Resource knowledge inventory can be developed further by addition of cross-disciplinary information, such as cyber failures in other domain than critical infrastructures.

Developing a resource knowledge inventory may be a controversial research area in terms of the exposing failure resources to the public and the adverse consequences of training offenders. However, offenders already communicated each other and shared their knowledge through dark web (Weiss and Bailetti, 2015). Resource knowledge inventory is a form of sharing the information about the lessons learned from previous failures to raise awareness and proactively mitigate future cyber failures.

Global contribution to share the experiences and knowledge in a united organized inventory can provide a reference for future junior designers and other stakeholders of systems dealing with security concerns as a heads up about potential failure in their systems. 
The descriptions of cyber failures developed in Section 3.2.3 were used to prepare a draft of resource knowledge inventory using the process defined in Section 3.2.2 in following steps:

\subsubsection{Failure Analysis}

The process uses traditional failure analysis methods such as developing scenario trees to identify the resources that indicated or contributed to each cyber failure. To develop a scenario tree, the failure description was reviewed, end-states (ES) or midstates (MS) were identified. Then, the resources that indicated or contributed to each state were added to the tree. This trend was continued until the initiating states (IS) of the scenario tree were identified. It is likely to be open-ended trend since each state has relevant enabling resources; however, Kaplan et al. (1999) suggested to include at least the most important resources. The outcome of developing scenario trees was identification of the resources that contributed to each cyber failure.

\subsubsection{Classification of resources}

The identified resources were classified to develop an organized draft of resource knowledge inventory. Since the inventory eventually will be used as a reference to predict cyber failures, it needs to have proper order to facilitate retrieving resources.

Literature review demonstrates diverse classifications for resources in the cyber world to address topological, functional, and dynamics of resources that contributed to 
the cyber failures (Christensen and Kaufman ,2006; Syed et al., 2016; Van Heerden et al., 2012). To the knowledge of researcher, a comprehensive classification with clear boundaries has not been developed yet and different classifications have been offered for the same or similar set of resources.

In this research, Unified Cybersecurity Ontology (Syed et al., 2016) was chosen to represent the typology of the identified resources. The classes without any matched resources were dismissed from classification of this research (i.e. attacker, exploit). The resources were classified in six typologies of 1) Indicators, 2) Tools, 3) People, 4) Ways, 5) Vulnerabilities, and 6) Information. This classification can be modified for more clarification. Organization of shared information in cyber space to communicate with different disciplines is a new emerging area that needs further investigation and research.

Table 3 provides a succinct definition of six types used to organize the resources that enabled cyber failures. For each resource type, an example is provided.

\begin{tabular}{|l|l|l|l|}
\hline & Types & Relevant Resource Description & Examples \\
\hline 1 & Indicators & $\begin{array}{l}\text { Resources that provide evidence of a } \\
\text { failure }\end{array}$ & Destroyed generator \\
\hline 2 & Tools & $\begin{array}{l}\text { Software and devices used to produce a } \\
\text { failure }\end{array}$ & Port scanner \\
\hline 3 & People & Humans that caused the failure to occur & Insider with knowledge \\
\hline 4 & Ways & $\begin{array}{l}\text { Methods and techniques used to cause the } \\
\text { failure }\end{array}$ & Phishing email \\
\hline 5 & Vulnerabilities & $\begin{array}{l}\text { Specific element of a system that opens } \\
\text { system to attack or damage }\end{array}$ & Dial-up connection \\
\hline 6 & Information & $\begin{array}{l}\text { Knowledge or facts learned, especially } \\
\text { about a certain subject or event }\end{array}$ & $\begin{array}{l}\text { List of vulnerabilities of } \\
\text { a device }\end{array}$ \\
\hline
\end{tabular}

Table 3-Classification of resources in cyber failures in critical infrastructure

\subsubsection{Developing a draft of resource knowledge inventory}


The draft of a resource knowledge inventory was developed by compiling the classified resources of the identified cyber failures. The set of organized resources of each scenario represents a row in the table of resource knowledge inventory which the columns signify the classification of resources noted in Section 3.2.4.2. The draft of resource knowledge inventory was completed by positioning all the identified resources of the descriptions in the table. The draft of resource knowledge inventory was finalized after incorporating experts' feedback. The revised version of resource knowledge inventory can be referenced in future predictions.

\subsubsection{Revised process and resource knowledge inventory as per experts' review}

A review team constitute from three experts that have at least ten years' experience of cybersecurity in the critical infrastructure of Canada in either the public or private sectors. The review session was arranged by the researcher to present the research method and the results to all three experts. It included some time for each reviewer to provide feedback as well as a discussion and brainstorming part for further recommendations to enhance research's productivity by all participants.

Reviewers were asked to evaluate and provide feedback about development and application of process as well as the draft of resource knowledge inventory by providing answers to following questions which are defined according to Arend et al. (2015).

1) How well the proposed process was referenced to the literature of AFD method?

2) How well the proposed process was applied to credible number of cyber failures to extract valid observations? 
3) How well the following terms were defined in the research:

- Resources

- Classification and relevant boundaries

- The states of resources including: Indicator, initiating state(IS), mid-state(MS), and endstate (ES)

4) How well the assumption, rationales, and flows were clarified to extract the resources?

5) How well the identified resources were classified in resource knowledge inventory?

6) How well the research is fitting among assumptions in cyber domain in terms of ontology, epistemology, methodology and human nature?

7) How well the process and resource knowledge inventory are empirically testable?

8) How well the process and the resource knowledge inventory are understandable and implementable?

Expert's feedbacks were collected and documented after review session by the researcher to revise the process and the resource knowledge inventory.

\subsubsection{Potential resources that may cause failure and failure scenarios}

The outcome of the process which is organized in the resource knowledge inventory was tested in a sample system to identify the potential resources that may cause failure and to develop failure scenarios. The sample system is examined to identify the available resources of the system. Different phases of the system during considering, development, operation and maintenance need to be investigated to identify the resource that contributing to the system for comparison with the resource knowledge inventory. 
Resources can negatively affect systems either directly such as being used in a system without considering potentiality for corruption or indirectly when similar resources caused cyber failure in another system in the past. The resource knowledge inventory is the reference to identify the resources of the past cyber failures.

In the case matched resources were not found in the resource knowledge inventory the AFD method suggests to investigate each phase of the target system to find what can happen if that phase cannot be completed successfully. Therefore, it starts from a potential failure in each phase of the system and searches for the required resources to cause the failure. If necessary resources to cause failure is missing, it is suggested to create necessary resources from those resources that are available. Combination of invented failures in different phases results in predicted failure scenarios that called scenario structuring (Kaplan et al., 1999).

\subsubsection{Enablers and constraints of using AFD method to predict cyber failures using publicly available knowledge}

The practical process provided in this research influenced by AFD uses publicly available information to identify the resources, and shares the information in an organized resource knowledge inventory to provide insight and to prevent future failures. During this research the factors that enable or constrain application of the AFD method to use publicly available information to predict cyber failures will be documented. 


\subsection{Summary}

Chapter 3 describes the research method. The main motivation of this study was to identify enablers and constraints to use AFD method to predict failures using publicly available information of past failures in critical infrastructure. The constructive approach was used to define a process to predict potential failures using publicly available information about past cyber failures. The process analyzed cyber failure scenarios, identified and classified resources that contributed to those failures in the past. Resource knowledge inventory was developed by compiling the classified resources of the cyber failures. 


\section{Results}

The purpose of Chapter 4 is to provide the results of applying the process to the identified past cyber failures in critical infrastructures. Section 4.1 identifies the cyber failures examined in this research and their timeline as well as the study period. Section 4.2 describes the process defined to use publicly available information about past cyber failures in critical infrastructures to predict failures. Section 4.3 provides the failure descriptions and classified resource. Section 4.4 provides the resource knowledge inventory. Section 4.5 describes experts' feedback on the process defined in this research and the resource knowledge inventory produced. Section 4.6 provides potential resources that may cause failure and failure scenarios for a sample system. Finally, Section 4.7 provides enablers and constraints of using AFD method to predict failures using publicly available information.

\subsection{Sample, timeline and study period}

Table 4 demonstrates the ten descriptions of past cyber failures in critical infrastructures identified according to defined criteria for samples. Identified scenarios were consulted with a security expert with 25 years' experience protecting the critical infrastructure of the government of Canada to validate the sample. 


\begin{tabular}{|c|c|c|c|c|}
\hline & $\begin{array}{l}\text { Name of } \\
\text { Cyber } \\
\text { Failure }\end{array}$ & $\begin{array}{l}\text { Time of failure } \\
\text { occurrence }\end{array}$ & $\begin{array}{l}\text { Indicator of cyber failure } \\
\text { at the end-state }\end{array}$ & Reason given for cyber failure \\
\hline S1 & Aurora & March 2007 & $\begin{array}{l}\text { Power generator } \\
\text { destroyed }\end{array}$ & $\begin{array}{l}\text { Unauthorized access to breakers to } \\
\text { open and close it quickly }\end{array}$ \\
\hline $\mathrm{S} 2$ & $\begin{array}{l}\text { Baku- } \\
\text { Tbilisi- } \\
\text { Ceyhan } \\
\text { (BTC) } \\
\text { Pipeline }\end{array}$ & Aug 2008 & Oil pipeline exploded & $\begin{array}{l}\text { Command of ICS were manipulated } \\
\text { by unauthorized access via the } \\
\text { network of surveillance camera to } \\
\text { computer network in valve station }\end{array}$ \\
\hline S3 & Stuxnet & June 2010 & $\begin{array}{l}\text { About } 1000 \text { centrifuges } \\
\text { in nuclear infrastructure } \\
\text { destroyed }\end{array}$ & $\begin{array}{l}\text { Command of ICS were manipulated } \\
\text { by unauthorized access via USB and } \\
\text { network's shared points to } \\
\text { programming software }\end{array}$ \\
\hline S4 & $\begin{array}{l}\text { RuggedC } \\
\text { om }\end{array}$ & 2012 & $\begin{array}{l}\text { Industrial Control } \\
\text { Systems Cyber } \\
\text { Emergency Response } \\
\text { Team (ICS- CERT) } \\
\text { published the threat to } \\
\text { critical infrastructures }\end{array}$ & $\begin{array}{l}\text { Backdoor provided unauthorized } \\
\text { remote access to communication } \\
\text { devices in the critical infrastructure }\end{array}$ \\
\hline S5 & Flame & May 28, 2012 & $\begin{array}{l}\text { Kaspersky Lab antivirus } \\
\text { discovered a malware in } \\
\text { computer system of } \\
\text { national oil company }\end{array}$ & $\begin{array}{l}\text { Modular malware is an espionage } \\
\text { toolkit that was used to exfiltrate top } \\
\text { secret files and send them to external } \\
\text { command and control }(\mathrm{C} \& \mathrm{C}) \text { servers }\end{array}$ \\
\hline S6 & $\begin{array}{l}\text { German } \\
\text { Power } \\
\text { Utility } \\
(50 \\
\text { Hertz })\end{array}$ & Nov 2012 & $\begin{array}{l}\text { Sustainable power utility } \\
\text { went out of service }\end{array}$ & $\begin{array}{l}\text { Distributed Denial of Service (DDoS) } \\
\text { attack with a botnet behind it }\end{array}$ \\
\hline S7 & Aramco & Aug 2012 & $\begin{array}{l}\text { Information in } 35,000 \\
\text { computers of a national } \\
\text { oil company was wiped } \\
\text { or destroyed }\end{array}$ & $\begin{array}{l}\text { Shamoon malware included modules } \\
\text { for self-copying, reporting and wiping } \\
\text { data, entered the computer network } \\
\text { via a response to a phishing email }\end{array}$ \\
\hline S8 & $\begin{array}{l}\text { German } \\
\text { Steel } \\
\text { Factory }\end{array}$ & 2013 & $\begin{array}{l}\text { Blast furnace of a steel } \\
\text { mill system could not be } \\
\text { shutdown }\end{array}$ & $\begin{array}{l}\text { Commands of ICS were manipulated } \\
\text { by an unauthorized access caused by } \\
\text { responding to a phishing email }\end{array}$ \\
\hline S9 & $\begin{array}{l}\text { Ukrainian } \\
\text { Electrical } \\
\text { Grid }\end{array}$ & Dec 23, 2015 & $\begin{array}{l}\text { Seven } 110 \mathrm{kV} \text { and } \\
\text { twenty-three } 35 \mathrm{kV} \\
\text { substations were } \\
\text { disconnected from the } \\
\text { grid }\end{array}$ & $\begin{array}{l}\text { Commands of ICS were manipulated } \\
\text { by an unauthorized access caused by } \\
\text { responding to a phishing email }\end{array}$ \\
\hline $\begin{array}{l}\mathrm{S} 1 \\
0\end{array}$ & $\begin{array}{l}\text { Kingo } \\
\text { database }\end{array}$ & June 2016 & $\begin{array}{l}\text { Confidential information } \\
\text { of } 18,800 \text { clients were } \\
\text { exposed in a web } \\
\text { database }\end{array}$ & $\begin{array}{l}\text { No password or another security } \\
\text { protocol was in use to protect data }\end{array}$ \\
\hline
\end{tabular}

Table 4- The ten cyber failure in critical infrastructures identified in criteria 
Table 4 illustrates the timeline for the ten cyber failure in the sample. The study period is from March 2007 to August 2016.

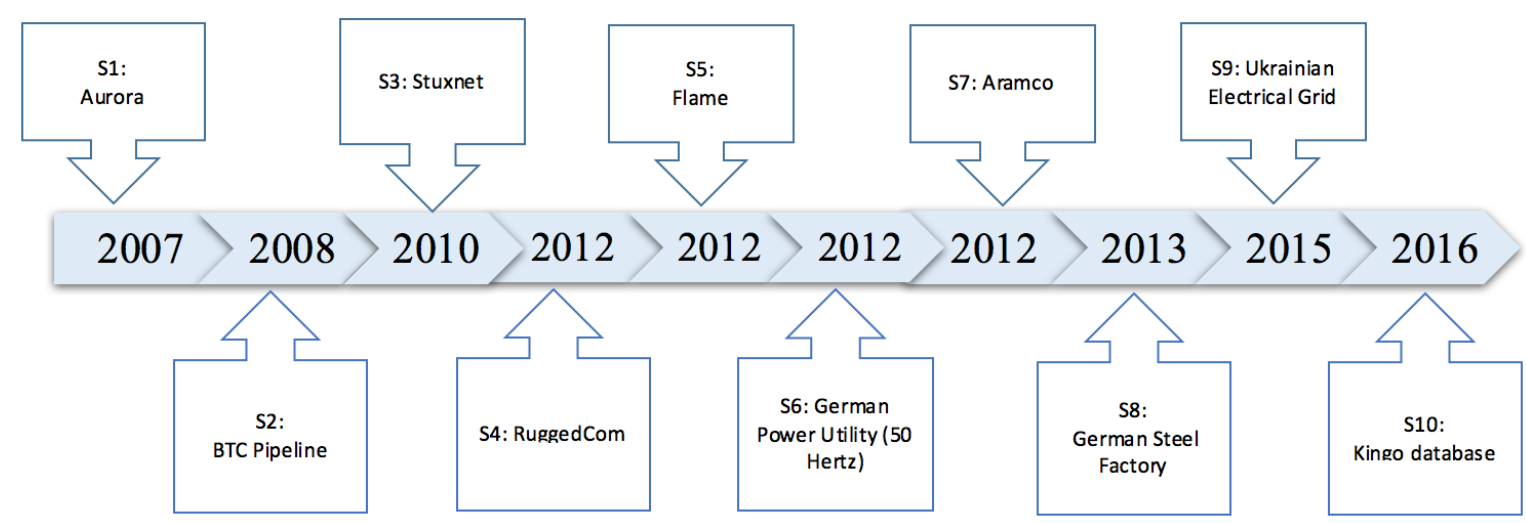

Figure 11- Timeline of past cyber failure in critical infrastructure included in the sample

The names of the cyber failures were chosen based on their labels in the respective literature. Table 5 represents the naming convention for the names of cyber failures.

\begin{tabular}{|l|l|l|}
\hline & Name of the cyber failure & Description \\
\hline 1 & Aurora & $\begin{array}{l}\text { The name that Idaho National Laboratory chose for the } \\
\text { test }\end{array}$ \\
\hline 2 & $\begin{array}{l}\text { Baku-Tbilisi-Ceyhan } \\
\text { (BTC) Pipeline }\end{array}$ & The location of the cyber failure \\
\hline 3 & Stuxnet & The name of software \\
\hline 4 & RuggedCom & The company that produced vulnerable products \\
\hline 5 & Flame & The name of software \\
\hline 6 & $\begin{array}{l}\text { German Power Utility } \\
(50 \text { Hertz) }\end{array}$ & The company that cyber failure took place. \\
\hline 7 & Aramco & The company cyber failure took place \\
\hline 8 & German Steel Factory & The company cyber failure took place \\
\hline 9 & Ukrainian Electrical Grid & The cyber failure location \\
\hline 10 & Kingo database & The company cyber failure took place \\
\hline
\end{tabular}

Table 5- Naming convention 


\subsection{The Process used publicly available information about past cyber failures in critical infrastructures to predict failures}

The process defined in Section 3.2.2 is used to analyze the ten cyber failures listed in Table 4 to identify the resources that indicated or contributed to the ten failures. Scenario trees are developed to analyze each cyber failure and to identify resources. The identified resources were classified according to classification stated in Table 3.

Classified resources of the ten cyber failures were compiled to develop a draft of resource knowledge inventory. The whole process and the draft of resource knowledge inventory were reviewed by cyber experts and feedbacks were incorporated. The revised resource knowledge inventory was used to predict cyber failure in a sample system. The predicted scenarios are the hypotheses for further study and consideration during design or reconfiguration process of systems for proactive mitigation.

\subsection{Cyber failure descriptions and resource}

For each of the ten past cyber failures in critical infrastructure included in Table 4 , the remainder of this section provides the ten failure descriptions and classified resources extracted from publicly available information in defined criteria. Appendix C includes scenario trees developed for the ten descriptions to analyze the cyber failures and to identify the list of resources contributed to each cyber failure. In failure analysis the relationship between the resources were not addressed in this research and scenario trees were only developed to identify the resources of each state from the literature. 


\subsubsection{Aurora (2007)}

In March 2007, Idaho National Laboratory experimented with a simulated failure in electrical infrastructure that falsified commands from ICS led to physical damage to power infrastructure. In this experiment, rapid open-and-close commands to a breaker connected to a generator in the substation-level, led to smoke emissions from the generator and destroyed it. The failure happened because of "out of synchronism connection of the generator to the grid" (Srivastava et al., 2013). The Aurora cyber failure is among the vulnerabilities of critical infrastructure identified by researchers.

Srivastava et al. (2013) indicated two attack models to damage the generator: local attack (Scenario 1) and remote breaker attack (scenario 2). In Scenario 1, the attack was proposed by inside access to a breaker -or breakers- within a generation level substation; this should have been carried out having insider knowledge and access. In Scenario 2, remote breakers- or a breaker or connected relays to them- were targeted to be opened and closed quickly through manipulated commands. According to Ralethe (2015), old encryption standards made the system vulnerable to data manipulation by unauthorized access.

Vulnerabilities in Ethernet connection and dial up connections enable attackers to breach into the network and make unauthorized access. If the network topology had Ethernet connection, port scanner applications such as Zmap or Masscan could have been used to make unauthorized access to the network. If the network had dial up connection with serial port RS-232 (more vulnerable), MODBUS (Modicon-Bus) address scanner could have been used to make unauthorized access to the network. Having knowledge about finger printing, discovery, access, detection, and connection speed helps offenders 
to find a vulnerable relay or breaker in the ICS to manipulate commands (Srivastava et al., 2013).

Table 6 provides the resources drawn from the Aurora description. Resources that led to the failure are organized into six types. The resources shown in Table 6 will be used in the resources knowledge inventory to make predictions in later steps.

\begin{tabular}{|c|c|c|c|}
\hline & Type & Resources in Scenario 1 & Resources in Scenario 2 \\
\hline 1 & Indicator & Generator destroyed & Generator destroyed \\
\hline 2 & Tools & Breaker or breakers, generator & $\begin{array}{l}\text { Breaker or breakers or } \\
\text { connected relays to them, } \\
\text { generator, port scanner(i.e. } \\
\text { Zmap, Masscan), MODBUS } \\
\text { address scanner }\end{array}$ \\
\hline 3 & People & Insider with access & \\
\hline 4 & Ways & $\begin{array}{l}\text { Open and close the breaker } \\
\text { quickly }\end{array}$ & $\begin{array}{l}\text { Commands to the breakers } \\
\text { manipulated via unauthorized } \\
\text { access }\end{array}$ \\
\hline 5 & $\begin{array}{l}\text { Vulnerabilit } \\
\text { ies }\end{array}$ & $\begin{array}{l}\text { Out of synchronism connection } \\
\text { of the generator to the grid }\end{array}$ & $\begin{array}{l}\text { Out of synchronism connection } \\
\text { of the generator to the grid, old } \\
\text { encryption standards, Ethernet } \\
\text { and dial-up connection } \\
\text { vulnerabilities }\end{array}$ \\
\hline 6 & Information & Insider knowledge & $\begin{array}{l}\text { Insider knowledge, Knowledge } \\
\text { about finger printing, } \\
\text { discovery, access, detection, } \\
\text { and connection speed }\end{array}$ \\
\hline
\end{tabular}

Table 6-Aurora resource types

\subsubsection{BTC Pipeline (2008)}

Initially, the explosion of the Baku- Tbilisi- Ceyhan (BTC) oil pipeline in 2008 was thought to be the result of a mechanical failure. Western intelligence services, however, found that the explosion was due to a cyberattack (Bloomberg, 2014). 
Taking advantage of the vulnerabilities in an IP-based camera and network design, offenders physically accessed camera and surveillance networks and penetrated to the computer network at the valve station and installed controlling software to enable future unauthorized access. They erased approximately sixty hours of pipeline surveillance videos, shut down alarms, cut off communications, jammed the backup satellite, superpressurizing the pipeline. Eventually, none of the alarms notified the workers of the incident; normal feedback was sent to the control room. Workers discovered the explosion 40 minutes after it occurred when they discovered the flames (Homeland Security News Wire, 2014).

Further investigations found that an infrared camera, working on a different network in the site, had recorded images of two men with laptops near the pipeline a few days before the explosion. The time of the image matched the time of the security breach of the pipeline system (Bloomberg, 2014).

Base on the provided description, resources of the BTC pipeline cyber failure are extracted and categorized in Table 7. 


\begin{tabular}{|c|c|c|}
\hline & Types & Resources \\
\hline 1 & Indicator & $\begin{array}{l}\text { Images of two men with laptops near the pipeline captured by } \\
\text { an infrared camera from a different network in the site, } 60 \\
\text { hours of surveillance videos erased, alarms shut down, } \\
\text { communication cut off, backup satellite jammed }\end{array}$ \\
\hline 2 & Tools & IP-based Camera \\
\hline 3 & People & Two men with laptops near the pipeline station \\
\hline 4 & Ways & $\begin{array}{l}\text { Physical access to camera, software installed for unauthorized } \\
\text { access in future, gas pressure increase in small station to } \\
\text { explode the pipeline }\end{array}$ \\
\hline 5 & Vulnerabilities & $\begin{array}{l}\text { Old encryption standards, IP base camera vulnerability, } \\
\text { network design vulnerabilities ( penetration from surveillance } \\
\text { network to ICS network) }\end{array}$ \\
\hline 6 & Information & $\begin{array}{l}\text { Time of the image in infrared camera matched with time of } \\
\text { security breach }\end{array}$ \\
\hline
\end{tabular}

Table 7-BTC pipeline resource types

\subsubsection{Stuxnet}

Stuxnet was malicious software found in the nuclear infrastructures of Iran in 2010, which caused physical damages to approximately 1000 centrifuges by providing unauthorized access and data manipulation in the ICS. Stuxnet was not detectable for several months, and it is believed that- being supported by insider knowledge- the codes were spread in the networks of stakeholders to gather information and find a way to the target (Wangen, 2015).

Stuxnet breached Microsoft Windows vulnerabilities and mined SQL servers to steal the data of the field devices, PLC model numbers, and IP addresses. Then, by identifying the target, Siemens PLC's responsible to control motor frequency converters in centrifuges, Stuxnet systematically searched the network to find them (Combs, 2011). 
Stuxnet was connected to command and control (C\&C) servers via LAN and network, for updates, uploading and execution codes. Stuxnet spread by self-copying via network shared points, taking advantage of vulnerabilities in Microsoft Windows, using LNK shortcuts of USB sticks, and gaining access to print spoolers of shared printers to gain unauthorized system-level access to lockdown computers used to program Siemens PLCs (Wangen, 2015).

Stuxnet used vulnerabilities in Siemens Step 7 software and manipulated data about motors' speed that caused centrifuges to be destroyed (Combs, 2011). Also, it manipulated data in alarms and control systems so during the failure process, none of the sensors or alarms triggered, and controlling systems were presenting normal readings until centrifuges' abnormality was finally observed in the stations (Kushner, 2013).

Table 8 provides Stuxnet resource types base on provided description.

\begin{tabular}{|l|l|l|}
\hline $\mathbf{1}$ & Types & Resources \\
\hline $\mathbf{2}$ & Tools & $\begin{array}{l}\text { Centrifuges' abnormality } \\
\text {, LAN and network, C\&C server, SQL server, stakeholders } \\
\text { network }\end{array}$ \\
\hline $\mathbf{3}$ & People & Insider with knowledge \\
\hline $\mathbf{4}$ & Ways & $\begin{array}{l}\text { Self-copying codes to spread via network shared points to } \\
\text { make unauthorized access to lockdown computers used to } \\
\text { program PLCs, manipulated data in Siemens Step 7 software } \\
\text { that changes motors' speed in centrifuges, manipulated data in } \\
\text { alarms and control systems }\end{array}$ \\
\hline $\mathbf{5}$ & Vulnerabilities & $\begin{array}{l}\text { Microsoft Windows vulnerability, Siemens Step7 software } \\
\text { vulnerability, shared point in system (vulnerable topology } \\
\text { design), alarm and sensors vulnerability to unauthorized access } \\
\text { (vulnerable security system) }\end{array}$ \\
\hline $\mathbf{6}$ & Information & $\begin{array}{l}\text { IP and model of PLC responsible to control motor frequency } \\
\text { converters in centrifuges }\end{array}$ \\
\hline
\end{tabular}

Table 8-Stuxnet resource types 


\subsubsection{RuggedCom}

RuggedCom is a Siemens company that produces network equipment for harsh environments, such as traffic control systems, railroad communication systems, power plants, electrical substations, and military sites, while also producing serial-to-IP conversions in SCADA systems that are supported by MODBUS and DNP3 protocols (ICS-CERT, 2012).

In May 2012, Industrial Control Systems Cyber Emergency Response Team (ICSCERT) web page published an article about the vulnerability of the "weak cryptography for password" which made a default backdoor for unauthorized access in all RuggedCom products manufactured before 2012 .

RuggedCom Remote Operating System (ROS) contained an undocumented backdoor account. The username for the account, "factory", cannot be disabled and its password is dynamically generated using the Media Access Control (MAC) address of the devices (ICS-CERT, 2012). This vulnerability can be remotely exploited by discovering the MAC address of the system by the attacker with minimum skills using online scripts (ICS-CERT, 2012; North American Electric Reliability Corporation public disclosure, 2012; Malashenco et al., 2012). Based on the provided description, Table 9 presents RuggedCom resource types. 


\begin{tabular}{|l|l|l|}
\hline & Types & Resources \\
\hline $\mathbf{1}$ & Indicator & RuggedCom products before 2012 \\
\hline $\mathbf{2}$ & Tools & \\
\hline $\mathbf{3}$ & People & \\
\hline $\mathbf{4}$ & Ways & Unauthorized access to RuggedCom devices \\
\hline $\mathbf{5}$ & Vulnerabilities & Weak cryptography for password (Backdoor) \\
\hline $\mathbf{6}$ & Information & Online scripts, MAC address of devices \\
\hline
\end{tabular}

Table 9-RuggedCom resource types

\subsubsection{Flame}

Flame is a cyber worm constitute modules to conduct espionage attacks, discovered in the network of the Iran National Oil Company, by Russia-based antivirus firm Kaspersky Lab, in May 2012. Flame targeted the vulnerabilities in various Microsoft Windows platforms, using multiple propagation and code injection methods, spread over local networks through shared printers and USB sticks by using print spooler and LNK shortcuts respectively. Flame used a fake proxy for Windows Update to bypass all security mechanisms, gained system level access to lockdown computers, and distributed into the network (Bencsáth, et al.,2012; Wangen et al., 2015).

Flame was equipped with modules to take screenshots, was able to switch on microphones and web cameras (if available) to record audio from the Skype conversations and environment, could browse through attached storage devices, and was able to spy through PDF files and AutoCAD files to steal top secret information. It could $\log$ keystrokes, extract geolocations from images and perform Bluetooth function to map devices in area, spy the network traffic, and send data via Bluetooth or through the network. Flame has modules to compress, encrypt, and save all stolen information in a database and send it to C\&C server regularly in small packages depend on the network 
traffic (Bencsáth et al., 2012). Table 10 shows Flame resource types based on the provided description.

\begin{tabular}{|c|c|c|}
\hline & Types & Resources \\
\hline 1 & Indicator & $\begin{array}{l}\text { Russia-based antivirus firm Kaspersky Lab that found the } \\
\text { worm }\end{array}$ \\
\hline 2 & Tools & $\begin{array}{l}\text { Multiple propagation and code injection methods, LNK } \\
\text { shortcuts of USB sticks, print spooler of shared printer, } \\
\text { modules to take screenshots, modules to record audio from } \\
\text { environment by switching on microphone, web camera or from } \\
\text { Skype conversation, modules to browse through attached } \\
\text { storage devices, modules to spy PDF and AutoCAD files to } \\
\text { steal top secret information and extract geolocations from } \\
\text { images, modules to log keystrokes, and modules to perform } \\
\text { Bluetooth function to map devices in area, modules to } \\
\text { compress and encrypt and save data in a database, modules to } \\
\text { spy the network traffic and send data to C\&C server in small } \\
\text { packages via Bluetooth or network, microphone, web camera, } \\
\text { monitors, keyboards }\end{array}$ \\
\hline 3 & People & \\
\hline 4 & Ways & $\begin{array}{l}\text { Cyber worm that made unauthorized system-level access to } \\
\text { lockdown computers, fake proxy for Window update to bypass } \\
\text { security mechanism, modules to conduct espionage attacks }\end{array}$ \\
\hline 5 & Vulnerabilities & Microsoft Windows vulnerability \\
\hline 6 & Information & \\
\hline
\end{tabular}

Table 10- Flame resource types

\subsubsection{German Power Utility (50 Hertz)}

A German power utility, specializing in sustainable energy, had been under cyberattack for five days in December 2012. According to EurActiv report, the CEO of 50 Hertz, Boris Schucht, the attack was a DDOS (Distributed Denial of Service) attack to the network with a botnet behind it. It blocked the internet domains for a couple of hours, and all email and connectivity via the internet was disrupted. Although, the email system has recovered in a short time, the whole system was fixed after five days, thankfully none of the electricity supplies were affected by the failure (EurActive, December 10, 2012; 50 
hertz annual report, 2012). Table 11 presents German power utility (50 Hertz) resource types according to provided description.

\begin{tabular}{|l|l|l|}
\hline & Types & Resources \\
\hline $\mathbf{1}$ & Indicator & Internet domaines' blockage, emails' disruption \\
\hline $\mathbf{2}$ & Tools & Botnet \\
\hline $\mathbf{3}$ & People & \\
\hline $\mathbf{4}$ & Ways & Distributed Denial of Service \\
\hline $\mathbf{5}$ & Vulnerabilities & Network \\
\hline $\mathbf{6}$ & Information & \\
\hline
\end{tabular}

Table 11- German power utility (50 Hertz) resource types

\subsubsection{Aramco}

Saudi Arabian Oil Company "Saudi Aramco" was targeted by a modular malware named Shamoon on August 15, 2012. Employees noticed the incident when files were disappeared and computers were failed. Approximately 30,000 computers were affected in this attack, but industrial control systems were not disturbed since they were working in separate networks (Bronk and Tikk-Ringas, 2013; MoneyCNN 2015).

Still, it is not known how Shamoon first infected the system. Some resources stated that the initial reason was a response to a phishing email. Shamoon is self-copying malware which copies and executes itself using vulnerabilities in network and security mechanisms (Wangen, 2015; Zhioua, 2013).

Shamoon has three basic modules; dropper, reporter, and wiper. The dropper includes codes to make unauthorized access to other components of systems, installs the malware, and drops the modules. The reporter sends the stolen data back to the initial 
attacker via typical HTTP GET request. The wiper, focuses on some targeted files with the names of download, document, picture, music, video, and desktop; to copy, rewrite, and delete them. Finally, it executes master boot records to destroy the disk sectors (Zhioua, 2013). Table 12 presents Aramco resource types based on provided description.

\begin{tabular}{|l|l|l|}
\hline & Types & Resources \\
\hline $\mathbf{1}$ & Indicator & Disappeared files, fail in 30,000 computers \\
\hline $\mathbf{2}$ & Tools & $\begin{array}{l}\text { Email contained malicious link to install malware } \\
\text {, Shamoon Malware (modular) ; dropper module to install the } \\
\text { malware via unauthorized access to other components; reporter } \\
\text { module to send data; wiper module to copy, rewrite and delete } \\
\text { files ; HTTP Get request; master boot records to destroy the } \\
\text { disk sector }\end{array}$ \\
\hline $\mathbf{3}$ & People & Insider who responded to phishing email \\
\hline $\mathbf{4}$ & Ways & $\begin{array}{l}\text { Codes to make unauthorized access, respond to a phishing } \\
\text { email, target files with names of download, document, picture, } \\
\text { music, video, desktop }\end{array}$ \\
\hline $\mathbf{5}$ & Vulnerabilities & Network vulnerability, security mechanism vulnerability \\
\hline $\mathbf{6}$ & Information & \\
\hline
\end{tabular}

Table 12-Aramco resource type

\subsubsection{German Steel Factory}

In 2013, A German steel factory experienced a massive physical damage due to malfunction in some of their industrial control systems. Investigations demonstrated that an insider's response to the phishing email with a compromised PDF file attached caused malicious codes to gain unauthorized access to the corporate network. The codes were self-executed at the time of opening, bypassed security mechanism taking advantage of vulnerabilities, and connected the attacker to the corporate network (Lee et al., 2014).

It is believed that having insider knowledge as well as ICS knowledge, such as using key loggers and network scanners, led attackers to exploit small sets of 
workstations. They used vulnerabilities in Active Directory to allow unauthorized access to ICS networks through corporate network. Codes that manipulated data in ICS system, caused breakdowns in ICS that eventually evaded appropriate furnace shutdowns and caused massive physical damage to the system (Lee et al., 2014). Table 13 presents German steel factory resource types based on provided description.

\begin{tabular}{|l|l|l|}
\hline & Types & Resources \\
\hline $\mathbf{1}$ & Indicator & Breakdown in ICS system, furnace cannot be shutdown \\
\hline $\mathbf{2}$ & Tools & Key logger, network scanner, self-executing codes \\
\hline $\mathbf{3}$ & People & Insider who responded to a phishing email \\
\hline $\mathbf{4}$ & Ways & $\begin{array}{l}\text { Codes to allow unauthorized access to ICS network, codes that } \\
\text { manipulated data in ICS, respond to the email contained } \\
\text { compromised PDF file attached }\end{array}$ \\
\hline $\mathbf{5}$ & Vulnerabilities & $\begin{array}{l}\text { Security mechanism vulnerabilities, Active Directory } \\
\text { vulnerabilities caused unauthorized access to ICS network }\end{array}$ \\
\hline $\mathbf{6}$ & Information & ICS knowledge \\
\hline
\end{tabular}

Table 13-German steel factory resource types

\subsubsection{Ukrainian Power Grid}

Kyivoblenergo's public announcement in December 2015 indicated a significant cyber failure in the Ukraine power infrastructure which caused the disconnection of seven $110 \mathrm{kV}$ substations and twenty-three $35 \mathrm{kV}$ substations from the grid. Additionally, two other utilities were malfunctioning and a technical problem occurring at their call center, was avoiding contacts of clients during the blackout. Approximately 700, 000 people were suffered from these incidents (Trivellato and Murphy, 2016).

An insider's response to a phishing email with an Excel document attached caused the network to be compromised with the codes allowing unauthorized access. Security mechanism vulnerabilities helped offenders to penetrate from main servers to ICS. Then, 
the codes manipulated data in SCADA, using backdoors in SCADA components, to open the breakers. It was believed that in some substations, breakers were opened with direct commands and SCADA systems were not able to re-close them, so the staff manually fixed the problems (Trivellato and Murphy, 2016).

Codes to disable sensors, alarm systems, ICS responses, and restart commands prevented utilities staff from sighting and fixing the problem to delay awareness process at control stations. Meanwhile, a denial of service attack (DOS) happened at their call center for the same purpose. Table 14 presents Ukrainian power grid resource types based on provided description.

\begin{tabular}{|c|c|c|}
\hline & Types & Resources \\
\hline 1 & Indicator & $\begin{array}{l}\text { Disconnection of seven } 110 \mathrm{kV} \text { substations and twenty-three } \\
35 \mathrm{kV} \text { substations from the grid and malfunctioning in two } \\
\text { utilities, problem in call center }\end{array}$ \\
\hline 2 & Tools & BlackEnergy malware campaign, KillDisk malware \\
\hline 3 & People & Insider who responded to a phishing email \\
\hline 4 & Ways & $\begin{array}{l}\text { Direct commands to breakers, codes to manipulate data in } \\
\text { SCADA to open the breakers, DOS attack to call center, delay } \\
\text { awareness process at control station, codes to disable ICS } \\
\text { response and restart commands to prevent fixing the problem, } \\
\text { codes to disable sensors and alarms to prevent staff from } \\
\text { sighting the problem, codes to allow unauthorized access to the } \\
\text { network, respond to the email contained infected Excel file } \\
\text { attached }\end{array}$ \\
\hline 5 & Vulnerabilities & $\begin{array}{l}\text { Backdoor in SCADA components, security mechanism } \\
\text { vulnerabilities(penetration from main server to ICS system) }\end{array}$ \\
\hline 6 & Information & \\
\hline
\end{tabular}

Table 14- Ukrainian power grid resource type

\subsubsection{Kingo Database}


In June 2016, the MacKeeper security research team found a web database with no password and the security protocol contained 40 gigabytes of confidential information of customers from an energy start-up, Kingo, accessible on the internet (ZDNet, 2016).

Kingo provides prepaid solar power systems to remote area customers in Guatemala and South Africa by collecting a copy of their national card or passport and providing them with prepaid codes for top-ups. Kingo was saving customer's data, detail of contracts, energy usage, support requests, and other data in a cloud service database (Ant). 18,800 customers' full names, addresses, exact GPS locations of homes, occupations, cell phone numbers, unique state identification numbers, genders, marital statuses, nationalities, the birthplaces, and some pictures, finger prints and signatures were among the exposed data (ZDNet, 2016).

Professional search engines such as Shodan.io can easily locate unprotected webcams, systems, and databases to abuse vulnerable data and violate human rights by private surveillance, which are common between drug cartels and extractivists (ZDNet, 2016). Table 15 presents Kingo's database resource types based on provided description.

\begin{tabular}{|l|l|l|}
\hline & Types & Resources \\
\hline $\mathbf{1}$ & Indicator & MacKeeper security research team \\
\hline
\end{tabular}




\begin{tabular}{|l|l|l|}
\hline $\mathbf{2}$ & Tools & Professional search engines such as Shodan.io \\
\hline $\mathbf{3}$ & People & Energy start-up customers \\
\hline $\mathbf{4}$ & Ways & Human rights violation (murder or private surveillance) \\
\hline $\mathbf{5}$ & Vulnerabilities & Unprotected database saved on the cloud \\
\hline $\mathbf{6}$ & Information & $\begin{array}{l}\text { Confidential data }(18,800 \text { customers' full name, address, exact } \\
\text { GPS location of home, occupation, cell phone number, unique } \\
\text { state identification number, sex, marital status, nationality, the } \\
\text { birthplace, and some pictures, finger prints and signatures) }\end{array}$ \\
\hline
\end{tabular}

Table 15- Kingo database resource type

\subsection{Draft of resource knowledge inventory}

The outcomes of Section 4.3 including classified resources of the ten cyber failures in critical infrastructures, were compiled to develop a draft of resource knowledge inventory.

Table 16 demonstrates the draft of resource knowledge inventor 


\begin{tabular}{|c|c|c|c|c|c|c|}
\hline & Indicator & Tool & People & Way & Vulnerability & Information \\
\hline Aurora-S1 & $\begin{array}{l}\text { Generator } \\
\text { destroyed }\end{array}$ & $\begin{array}{l}\text { Breaker or breakers, } \\
\text { generator }\end{array}$ & $\begin{array}{l}\text { Insider } \\
\text { with } \\
\text { access }\end{array}$ & $\begin{array}{l}\text { Open and close the } \\
\text { breaker quickly }\end{array}$ & $\begin{array}{l}\text { Out of synchronism } \\
\text { connection of the generator to } \\
\text { the grid }\end{array}$ & $\begin{array}{l}\text { Insider } \\
\text { knowledge }\end{array}$ \\
\hline Aurora-S2 & $\begin{array}{l}\text { Generator } \\
\text { destroyed }\end{array}$ & $\begin{array}{l}\text { Breaker or breakers or } \\
\text { connected relays to them, } \\
\text { generator, port } \\
\text { scanner(i.e. Zmap, } \\
\text { Masscan), MODBUS } \\
\text { address scanner }\end{array}$ & & $\begin{array}{l}\text { Commands to the } \\
\text { breakers manipulated } \\
\text { via unauthorized } \\
\text { access }\end{array}$ & $\begin{array}{l}\text { Out of synchronism } \\
\text { connection of the generator to } \\
\text { the grid, old encryption } \\
\text { standards, Ethernet and dial- } \\
\text { up connection vulnerabilities }\end{array}$ & $\begin{array}{l}\text { Insider } \\
\text { knowledge, } \\
\text { Knowledge } \\
\text { about finger } \\
\text { printing, } \\
\text { discovery, } \\
\text { access, } \\
\text { detection, } \\
\text { and } \\
\text { connection } \\
\text { speed }\end{array}$ \\
\hline $\begin{array}{l}\text { BTC } \\
\text { Pipeline }\end{array}$ & $\begin{array}{l}\text { Images of two } \\
\text { men with } \\
\text { laptops near } \\
\text { the pipeline } \\
\text { captured by an } \\
\text { infrared } \\
\text { camera from a } \\
\text { different } \\
\text { network in the } \\
\text { site, } 60 \text { hours } \\
\text { of surveillance } \\
\text { videos erased, } \\
\text { alarms shut } \\
\text { down, } \\
\text { communication } \\
\text { cut off, backup } \\
\text { satellite } \\
\text { jammed }\end{array}$ & IP-based Camera & $\begin{array}{l}\text { Two men } \\
\text { with } \\
\text { laptops } \\
\text { near the } \\
\text { pipeline } \\
\text { station }\end{array}$ & $\begin{array}{l}\text { Physical access to } \\
\text { camera, software } \\
\text { installed for } \\
\text { unauthorized access } \\
\text { in future, gas } \\
\text { pressure increase in } \\
\text { small station to } \\
\text { explode the pipeline }\end{array}$ & $\begin{array}{l}\text { Old encryption standards, IP } \\
\text { base camera vulnerability, } \\
\text { network design vulnerabilities } \\
\text { ( penetration from } \\
\text { surveillance network to ICS } \\
\text { network) }\end{array}$ & $\begin{array}{l}\text { Time of the } \\
\text { image in } \\
\text { infrared } \\
\text { camera } \\
\text { matched } \\
\text { with time of } \\
\text { security } \\
\text { breach }\end{array}$ \\
\hline Stuxnet & Centrifuges' & LNK shortcuts of USB & Insider & Self-copying codes & Microsoft Windows & IP and model \\
\hline
\end{tabular}




\begin{tabular}{|c|c|c|c|c|c|c|}
\hline & Indicator & Tool & People & Way & Vulnerability & Information \\
\hline & abnormality & $\begin{array}{l}\text { sticks, print spooler of a } \\
\text { shared printer }\end{array}$ & $\begin{array}{l}\text { with } \\
\text { knowledge }\end{array}$ & $\begin{array}{l}\text { to spread via network } \\
\text { shared points to } \\
\text { make unauthorized } \\
\text { access to lockdown } \\
\text { computers used to } \\
\text { program PLCs, } \\
\text { manipulated data in } \\
\text { Siemens Step } 7 \\
\text { software that } \\
\text { changes motors' } \\
\text { speed in centrifuges, } \\
\text { manipulated data in } \\
\text { alarms and control } \\
\text { systems }\end{array}$ & $\begin{array}{l}\text { vulnerability, Siemens Step7 } \\
\text { software vulnerability, shared } \\
\text { point in system (vulnerable } \\
\text { topology design), alarm and } \\
\text { sensors vulnerability to } \\
\text { unauthorized access } \\
\text { (vulnerable security system) }\end{array}$ & $\begin{array}{l}\text { of PLC } \\
\text { responsible } \\
\text { to control } \\
\text { motor } \\
\text { frequency } \\
\text { converters in } \\
\text { centrifuges }\end{array}$ \\
\hline RuggedCom & $\begin{array}{l}\text { RuggedCom } \\
\text { products } \\
\text { before } 2012\end{array}$ & & & $\begin{array}{l}\text { Unauthorized access } \\
\text { to RuggedCom } \\
\text { devices }\end{array}$ & $\begin{array}{l}\text { Weak cryptography for } \\
\text { password (Backdoor) }\end{array}$ & $\begin{array}{l}\text { Online } \\
\text { scripts, } \\
\text { MAC } \\
\text { address of } \\
\text { devices }\end{array}$ \\
\hline Flame & $\begin{array}{l}\text { Russia-based } \\
\text { antivirus firm } \\
\text { Kaspersky Lab } \\
\text { that found the } \\
\text { worm }\end{array}$ & $\begin{array}{l}\text { Multiple propagation and } \\
\text { code injection methods, } \\
\text { LNK shortcuts of USB } \\
\text { sticks, print spooler of } \\
\text { shared printer, modules to } \\
\text { take screenshots, modules } \\
\text { to record audio from } \\
\text { environment by switching } \\
\text { on microphone, web } \\
\text { camera or from Skype } \\
\text { conversation, modules to } \\
\text { browse through attached } \\
\text { storage devices, modules } \\
\text { to spy PDF and AutoCAD } \\
\text { files to steal top secret } \\
\text { information and extract } \\
\text { geolocations from images, }\end{array}$ & & $\begin{array}{l}\text { Cyber worm that } \\
\text { made unauthorized } \\
\text { system-level access } \\
\text { to lockdown } \\
\text { computers, fake } \\
\text { proxy for Window } \\
\text { update to bypass } \\
\text { security mechanism, } \\
\text { modules to conduct } \\
\text { espionage attacks }\end{array}$ & $\begin{array}{l}\text { Microsoft Windows } \\
\text { vulnerability }\end{array}$ & \\
\hline
\end{tabular}




\begin{tabular}{|c|c|c|c|c|c|c|}
\hline & Indicator & Tool & People & Way & Vulnerability & Information \\
\hline & & $\begin{array}{l}\text { modules to log } \\
\text { keystrokes, and modules } \\
\text { to perform Bluetooth } \\
\text { function to map devices in } \\
\text { area, modules to compress } \\
\text { and encrypt and save data } \\
\text { in a database, modules to } \\
\text { spy the network traffic } \\
\text { and send data to C\&C } \\
\text { server in small packages } \\
\text { via Bluetooth or network, } \\
\text { microphone, web camera, } \\
\text { monitors, keyboards }\end{array}$ & & & & \\
\hline $\begin{array}{l}\text { German } \\
\text { Power } \\
\text { Utility }\end{array}$ & $\begin{array}{l}\text { Internet } \\
\text { domaines' } \\
\text { blockage, } \\
\text { emails' } \\
\text { disruption }\end{array}$ & Botnet & & $\begin{array}{l}\text { Distributed Denial of } \\
\text { Service }\end{array}$ & Network & \\
\hline Aramco & $\begin{array}{l}\text { Disappeared } \\
\text { files, fail in } \\
30,000 \\
\text { computers }\end{array}$ & $\begin{array}{l}\text { Email contained } \\
\text { malicious link to install } \\
\text { malware } \\
\text {, Shamoon Malware } \\
\text { (modular); dropper } \\
\text { module to install the } \\
\text { malware via unauthorized } \\
\text { access to other } \\
\text { components; reporter } \\
\text { module to send data; } \\
\text { wiper module to copy, } \\
\text { rewrite and delete files; } \\
\text { HTTP Get request; master } \\
\text { boot records to destroy } \\
\text { the disk sector }\end{array}$ & $\begin{array}{l}\text { Insider } \\
\text { who } \\
\text { responded } \\
\text { to } \\
\text { phishing } \\
\text { email }\end{array}$ & $\begin{array}{l}\text { Codes to make } \\
\text { unauthorized access, } \\
\text { respond to a phishing } \\
\text { email, target files } \\
\text { with names of } \\
\text { download, document, } \\
\text { picture, music, video, } \\
\text { desktop }\end{array}$ & $\begin{array}{l}\text { Network vulnerability, } \\
\text { security mechanism } \\
\text { vulnerability }\end{array}$ & \\
\hline $\begin{array}{l}\text { German } \\
\text { Steel } \\
\text { Factory }\end{array}$ & $\begin{array}{l}\text { Breakdown in } \\
\text { ICS system, } \\
\text { furnace cannot }\end{array}$ & $\begin{array}{l}\text { Key logger, network } \\
\text { scanner, self-executing } \\
\text { codes }\end{array}$ & $\begin{array}{l}\text { Insider } \\
\text { who } \\
\text { responded }\end{array}$ & $\begin{array}{l}\text { Codes to allow } \\
\text { unauthorized access } \\
\text { to ICS network, }\end{array}$ & $\begin{array}{l}\text { Security mechanism } \\
\text { vulnerabilities, Active } \\
\text { Directory vulnerabilities }\end{array}$ & $\begin{array}{l}\text { ICS } \\
\text { knowledge }\end{array}$ \\
\hline
\end{tabular}




\begin{tabular}{|c|c|c|c|c|c|c|}
\hline & Indicator & Tool & People & Way & Vulnerability & Information \\
\hline & be shutdown & & $\begin{array}{l}\text { to a } \\
\text { phishing } \\
\text { email }\end{array}$ & $\begin{array}{l}\text { codes that } \\
\text { manipulated data in } \\
\text { ICS, respond to the } \\
\text { email contained } \\
\text { compromised PDF } \\
\text { file attached }\end{array}$ & $\begin{array}{l}\text { caused unauthorized access to } \\
\text { ICS network }\end{array}$ & \\
\hline $\begin{array}{l}\text { Ukrainian } \\
\text { Power Grid }\end{array}$ & $\begin{array}{l}\text { Disconnection } \\
\text { of seven } 110 \\
\mathrm{kV} \text { substations } \\
\text { and twenty- } \\
\text { three } 35 \mathrm{kV} \\
\text { substations } \\
\text { from the grid } \\
\text { and } \\
\text { malfunctioning } \\
\text { in two utilities, } \\
\text { problem in call } \\
\text { center }\end{array}$ & $\begin{array}{l}\text { BlackEnergy malware } \\
\text { campaign, KillDisk } \\
\text { malware }\end{array}$ & $\begin{array}{l}\text { Insider } \\
\text { who } \\
\text { responded } \\
\text { to a } \\
\text { phishing } \\
\text { email }\end{array}$ & $\begin{array}{l}\text { Direct commands to } \\
\text { breakers, codes to } \\
\text { manipulate data in } \\
\text { SCADA to open the } \\
\text { breakers, DOS attack } \\
\text { to call center, delay } \\
\text { awareness process at } \\
\text { control station, codes } \\
\text { to disable ICS } \\
\text { response and restart } \\
\text { commands to prevent } \\
\text { fixing the problem, } \\
\text { codes to disable } \\
\text { sensors and alarms to } \\
\text { prevent staff from } \\
\text { sighting the problem, } \\
\text { codes to allow } \\
\text { unauthorized access } \\
\text { to the network, } \\
\text { respond to the email } \\
\text { contained infected } \\
\text { Excel file attached }\end{array}$ & $\begin{array}{l}\text { Backdoor in SCADA } \\
\text { components, security } \\
\text { mechanism } \\
\text { vulnerabilities(penetration } \\
\text { from main server to ICS } \\
\text { system) }\end{array}$ & \\
\hline $\begin{array}{l}\text { Kingo } \\
\text { database }\end{array}$ & $\begin{array}{l}\text { MacKeeper } \\
\text { security } \\
\text { research team }\end{array}$ & $\begin{array}{l}\text { Professional search } \\
\text { engines such as Shodan.io }\end{array}$ & $\begin{array}{l}\text { Energy } \\
\text { start-up } \\
\text { customers }\end{array}$ & $\begin{array}{l}\text { Human rights } \\
\text { violation (murder or } \\
\text { private surveillance) }\end{array}$ & $\begin{array}{l}\text { Unprotected database saved } \\
\text { on the cloud }\end{array}$ & $\begin{array}{l}\text { Confidential } \\
\text { data }(18,800 \\
\text { customers' } \\
\text { full name, } \\
\text { address, } \\
\text { exact GPS } \\
\text { location of } \\
\text { home, }\end{array}$ \\
\hline
\end{tabular}




\begin{tabular}{|l|l|l|l|l|l|l|}
\hline & Indicator & Tool & People & Way & Vulnerability & Information \\
\hline & & & & & occupation, \\
cell phone \\
number, \\
unique state \\
identification \\
number, sex, \\
marital \\
\end{tabular}




\subsection{Revised process and revised resource knowledge inventory}

The feedbacks collected from three experts were incorporated in outcome of the research. The major concern was to clarify definition of resources, and boundaries for classification of the resources. Chapter 2 included the summary of the literature review about the resources however since the classification is still not matured in cyber domain, researcher classified the resources to the closest type based on the description. Future research is required to develop a solid ontology of resources to be used as a common language in the cyber domain.

\subsection{Potential resources that may cause failure and failure scenarios for a sample system}

The sample system that was investigated in this research was LTW-Start. LTWStart is a component of the Global Cybersecurity Resource that provides startups with key functionalities to help them globalize early and rapidly and be safer online. The intent is to provide functionality that allow the startup to grow its revenue, value, and importance quickly and through the use of carefully designed operating system, to be safer online. The LTW-Start, tagline is "Start global and safer."

The general architecture of LTW-Start is shown in Figure 12. The top level tier, tools, provides functions to help the entrepreneurial teams generate cash, manage customer discovery, find trusted suppliers, manage documents, create a website, and have corporate email. The lower tier, setting, refers to capabilities for configuring the "safer" 
operating system using ClearOS operating system- a strengthened operating system through minimization of function, addition of security tools, etc.

The plan is to deploy thousands of LTW-Starts around the world and that each LTW-Start would have act as a security sensor reporting to a security operations center.

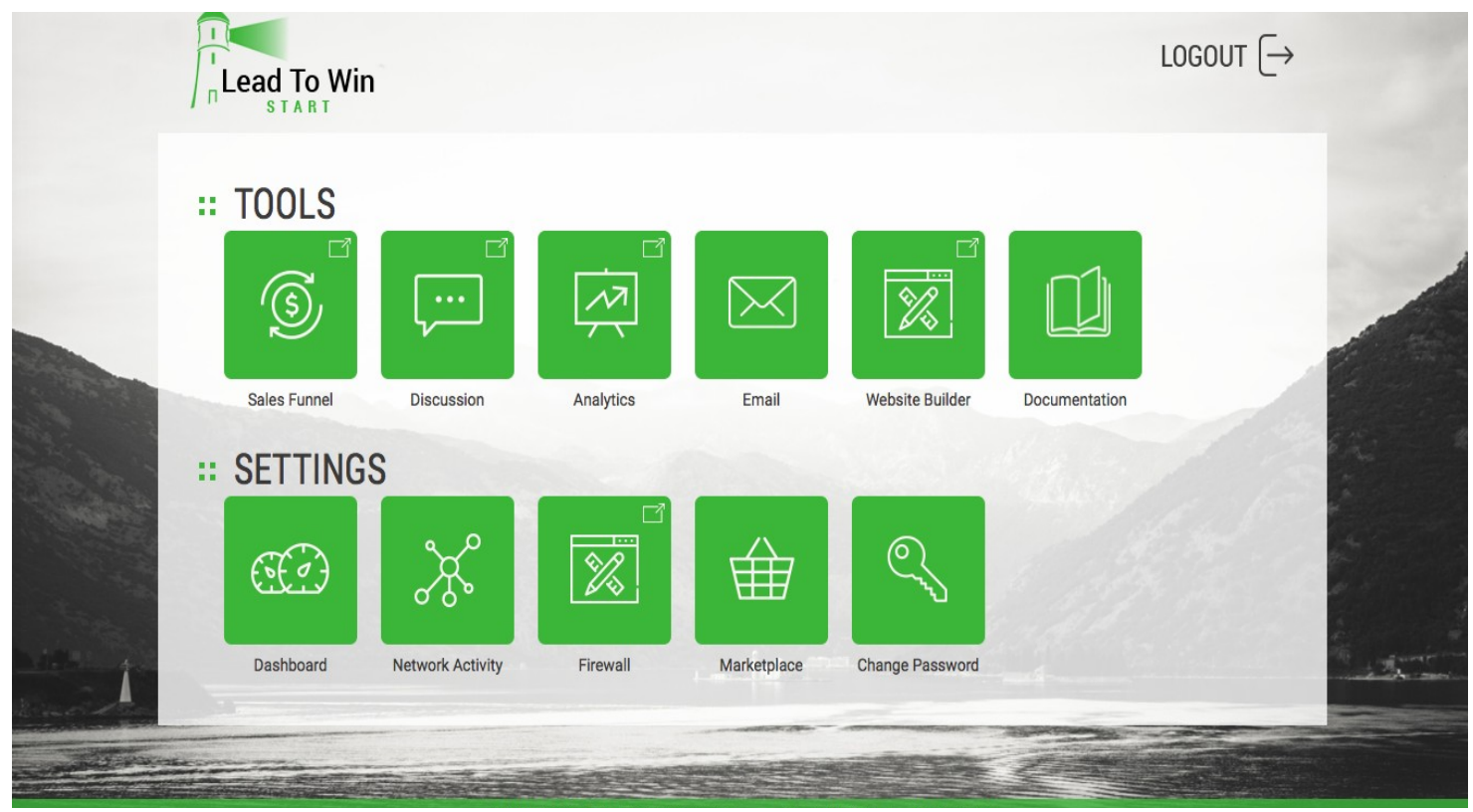

Figure 12- General architecture of LTW-Start

Investigation of the system indicated that the available resources in the system may result in following scenarios in comparison with the resource knowledge inventory. These scenarios are hypothesis for further test and validation while opens a new vision of security concern during developing cycles of the system.

Failure/Indicator: Security operations center receives false network flow information from substantial portion of LTW-Start sensors/installations. Sensor network 
is used for spamming campaign. Startup information is stolen.

Tools: Targeted phishing attack through email across sensor network

People:

(i) Targeted phishing campaign increases number of employees of companies who inadvertently succumb to psychological manipulation embedded in phishing email

(ii) Entrepreneurial startup has low cybersecurity talent and varied from expected behavior by reconfiguring underlying ClearOS operating system - unexpectedly turning off various security features

Ways: On clicking phishing email, malicious code is downloaded that immediately surveys OS. Code knows it is ClearOS and explores known vulnerabilities; code tests configuration and finds weak login credentials resulting in full access to ClearOS. Code downloads software to modify security reporting tools (reporting to security operations centre)

Vulnerabilities: Weak credentials, weak configuration allowing downloadable software, 0 -day vulnerability in operating systems potentially applicable but weak credentials means it is not needed

Information: Malware steals startup intellectual property 
Further concerns were discussed during the investigation session that opened a new perspective to the developer to think of potential failures that can happen in that system.

\subsection{Enablers and constraints of using AFD method to predict failures using publicly available information}

The enablers to use the AFD method to predict cyber failures were identified as:

1) Frequent contribution of same or similar resources indicates that proper

information sharing and preventive methods were not conveyed to all stakeholders and systems were vulnerable to the known failure resources. Resource knowledge inventory can help to distribute the knowledge properly. Specifically, to the junior operation level stakeholders to provide comprehensive knowledge about past cyber failures.

2) Although the AFD method insists on identifying all of the resources of a failure, AFD-2 invents the scenarios from existing resources. It can be concluded that every information about the past failure resources can be used to protect other systems in the case it properly shared to target audience.

3) Collection of the most up-to-date worldwide knowledge about potential failure resources can changes the priorities and enhance the awareness about cyber threats in different systems (Katz et al., 2016).

The constraints to use the AFD method to predict cyber failures were identified as: 
1) Although the reports indicated occurrence of hundred thousands of cyber failures around the world (McAfee, 2015), limited number of disclosed cyber failures is the bottleneck of knowledge transmission.

2) Confidential nature of information in cyber domain causes the constraints to extract information about detail of failures, success scenarios, components of systems, and mitigation methods and policies.

3) Different literatures demonstrate diverse descriptions about a same failure. Political perspectives and bias literature were the obstacles to find reliable information. 


\section{Discussion}

Chapter 5 is a discussion of the results provided in Chapter 4. Chapter 5 is organized in six sections. Section 5.1 indicated the challenges of developing the resource knowledge inventory. Section 5.2 discusses process validation. Section 5.3 discusses adaption problem. Section 5.4 discusses using resource knowledge inventory in operation level. Section 5.5 discusses predictions of cyber failure scenarios in a sample system. Finally, Section 5.6 links the results of the research to the reviewed literature.

\subsection{Challenges of developing the resource knowledge inventory}

Resource knowledge inventory was developed by extracting resources from publicly available information to compose descriptions of cyber failure. Lack of consistent format to describe the cyber failures resulted in diverse style of descriptions provided in Chapter 4. The researcher intended to include all of the resources that were available in public information.

Extracting information to find the failures that disclosed minimum number of resources was challenging due to the lack of inclusive database of cyber failures in public information. This was backing the necessity of developing resource knowledge inventory for stakeholders who desire to learn lessons from cyber failures.

Classification of resources was other challenge because to the knowledge of researcher no dominant ontology has been defined in cybersecurity with clear boundaries 
for classification. Different literatures provided different classification for the same set of resources. In this research the closest classification that include most of the identified resources was selected and the classes that were not representing any of the identified resources were not included in resource knowledge inventory.

Classified resources were organized with consideration of the main purpose of developing resource knowledge inventory, its application to predict cyber failures in different systems by stakeholders. Lack of usability rules at this stage makes it challenging to deliver the knowledge with proper application solutions.

\subsection{Process validation}

Due to the limitations in cyber domain to apply AFD method to predict cyber failures, the new process developed which required to be validated prior to application and test. Expert review incorporated in the process to review the results to avoid bias decision making. Due to immaturity of the domain it was challenging to define how experts can collaborate in validation of the process. A questionnaire developed based on the literature about theory-building assessment to address process validity in a structured format.

\subsection{Adoption problem}

The review of the resource knowledge inventory indicates that frequent combination of resources have been used in several cyber failures. For instance, emails with malicious link were used in three critical infrastructure cyber failures between 2012 
and 2015. Although, these vulnerabilities were known to the stakeholders, the adaption techniques and overall understanding about potential cyber failures in systems were not conveyed properly.

\subsection{Using resource knowledge inventory in operation level}

Recent controversial discussions and research regarding the significance of sharing information to enhance the overall understanding about potential threats of cyber failure, was practically demonstrated during the research to the researcher. Knowing that many contractors and third parties in small businesses that do not have access and budget to examine reliability of smart devices and their programming, still utilize smart devices in their product without considering the threats being imposed to the end user in critical infrastructure. For example, Aurora is the example of exposing the power grid to a significant failure by using SCADA components that are not well secured.

Developing resource knowledge inventory that organizes worldwide experiences of potential failures can broaden young engineers and designers' viewpoints about security concerns to find potential vulnerabilities of their designs prior to the releasing it to the market as well as restoring critical information of their design and related communication properly. Urging to apply this process autonomously from vulnerability assessment policies at end users' sites will definitely help to protect systems from cyber failures.

\subsection{Predictions of cyber failure scenarios in a sample system}


Investigation of potential cyber failures in LTW-Start system, showed that developers were more relied on linear failure analysis method rather than thinking to find a way to attack their systems. In some areas quite high-level security plan was considered, while there where some channels without proper security plan that make the whole system vulnerable. Several scenarios defined to cause cyber failure to the system that can be proactively mitigated with no cost.

\subsection{Link the results of research to the literature}

The review of results demonstrated that all of the ten cyber failure targets were designed and equipped with security mechanisms. Billions of dollars were spent to ensure reliability of the systems; However, all were exploited through the component of the systems and existing vulnerabilities. In some scenarios known vulnerabilities to critical infrastructure stakeholders caused cyber failure again later on (i.e., USB, shared printer). Even though identifying vulnerabilities has prime value, transmitting the knowledge to the wider operation level stakeholders should also be the top priorities. 


\section{Conclusion, limitations, and suggestions for future research}

Chapter 6 is organized into three sections. Section 6.1 provides the conclusions of this research. Section 6.2 identifies the limitations of this research. Section 6.3 provides suggestions for future research.

\subsection{Conclusion}

The anticipatory process developed and examined in this research to predict future cyber failures in technology startups resulted in developing the resource knowledge inventory as a reference for stakeholders of cyber infrastructures and small technology startups to predict cyber failure scenarios in their systems from a broader view to be mitigated in more cost-effective ways.

The resource knowledge inventory facilitates transmitting information about lessons learned from the past cyber failures in critical infrastructure to be used in noncritical infrastructures and technology startups that may less consider being a target of a cyberattack. The process developed in this research is influenced by the AFD method, while only using publically available information about past cyber failures for scenario structuring. Application of the AFD method to anticipate future cyber failures requires finding the solution, correction and final mitigation method that was not considered in criteria of this research.

Further development of the resource knowledge inventory to include crossdisciplinary knowledge of different cyber infrastructures will enrich the capability to 
predict future cyber failures and may provide new solutions for cybersecurity challenges. The worldwide cyber failure experience, as well as academic cyber failure studies, will provide insight to mitigate cyber failures if communicated to the stakeholders of cyber infrastructure properly.

Future cyber failure scenarios are structured based on communicated information between stakeholders.

\subsection{Limitations of the research}

This research has five major limitations. The first limitation was publicly available information that was narrowed to the results of search tools. However, expanding sources of information to include worldwide experiences from various disciplines will enrich the resource knowledge inventory. Global contribution to building the resource knowledge inventory by crowdsourcing will significantly enhance the efficiency of inventory to anticipate potential cyber failures scenarios.

The second limitation was the lack of solid classification to organize resources due to the immaturity of ontology definition in the cyber domain. A broader research is required to clarify the classification of ontology in cyberspace to facilitate organizing and sharing the information among various disciplines.

The third limitation was the challenge to develop cyber failure descriptions since the information should be formatted to be accessible from the inventory in future to 
develop cyber failure scenarios in different systems. The lack of usability guide made the development of failure descriptions and the resource knowledge inventory challenging.

The fourth limitation was the few number of disclosed newsworthy cyber failures in critical infrastructure, which were only ten cyber failures within last ten years, and very few of them have disclosed some details about the cyber failure resources. The small sample size avoided analysis of the results in terms of frequency, trends, and generalization of findings.

The fifth limitation was the practical test of the process. The challenge was extracting all existing resources and details in a sample system including the people, the processes, and all system interactions. Technical startups were not interested in disclosing their information and processes to be studied as a target for potential cyber failures.

\subsection{Suggestions for future research}

Three areas for future research are suggested in this research. The first suggestion is an open-source platform to engage worldwide stakeholders of cyber systems, to share or use the cross-disciplinary cyber failure experiences, in order to broaden the understanding about potential cyber failures in different systems. Crowdsourcing improves the quality, diversity, scalability of the resource knowledge inventory to communicate the information and to anticipate potential cyber failures more effectively. 
The second suggestion is to develop a knowledge inventory of mitigation methods, to include various mitigation methods, their strength, and weaknesses, to help stakeholders of cyber systems gain insight about pros and cons of different mitigation methods to enhance their systems' resilience.

The third suggestion is to execute a broader study to clarify ontology classification for cyber failure resources to facilitate knowledge sharing and cross-disciplinary experience dissemination. The enhanced understanding about potential cyber failure scenarios results in more efficient proactive strategies to improve systems' resilience. 


\section{References}

50 hertz annual report, 2012. Retrieved from:

www.50hertz.com/.../2012\%20EN/50Hertz-AnnualReport-2012-en.pdf

Ahmed, A., Kayis, B. and Amornsawadwatana, S., 2007. A review of techniques for risk management in projects. Benchmarking: An International Journal, 14(1), pp.22-36.

Arend, R.J., Sarooghi, H. and Burkemper, A., 2015. Effectuation as ineffectual?

Applying the $3 \mathrm{E}$ theory-assessment framework to a proposed new theory of entrepreneurship. Academy of Management Review, 40(4), pp.630-651.

Bencsáth, B., Pék, G., Buttyán, L. and Felegyhazi, M., 2012. The cousins of stuxnet:

Duqu, flame, and gauss. Future Internet, 4(4), pp.971-1003.

Bhuiyan, N., Gerwin, D. and Thomson, V., 2004. Simulation of the new product development process for performance improvement. Management science, 50(12), pp.1690-1703.

https://www.bloomberg.com/news/articles/2014-12-10/mysterious-08-turkey-pipelineblast-opened-new-cyberwar

Boyes, H.A., 2013, October. Trustworthy cyber-physical systems-A review. In System Safety Conference incorporating the Cyber Security Conference 2013, 8th IET International (pp. 1-8). IET.

Bronk, C. and Tikk-Ringas, E., 2013. The cyber attack on Saudi Aramco. Survival, 55(2), pp.81-96. 
Chen, F., 2002. Policies as design and implementation artifacts for non functional requirements.

Christensen, C.M. and Kaufman, S.P., 2006. Assessing your organization's capabilities: Resources, processes and priorities.

Clothier, R.A. and Walker, R.A., 2015. Safety risk management of unmanned aircraft systems. In Handbook of Unmanned Aerial Vehicles (pp. 2229-2275). Springer Netherlands.

Combs, M.M., 2011. Impact of the Stuxnet virus on industrial control systems. XIII International Forum Modern Information Society Formation Problems, Perspectives, Innovation Approaches, pp.5-10.

Dunjó, J., Fthenakis, V., Vílchez, J.A. and Arnaldos, J., 2010. Hazard and operability (HAZOP) analysis. A literature review. Journal of hazardous materials, 173(1), pp.1932.

http://www.euractiv.com/section/energy/news/european-renewable-power-grid-rockedby-cyber-attack/

Gay, L.F. and Sinha, S.K., 2012. Effective Resilience Assessment Methodology for Water Utilities (ERASMUS). Proceedings of the Water Environment Federation, 2012(15), pp.1902-1913.

GhasemiGol, M., Ghaemi-Bafghi, A. and Takabi, H., 2016. A comprehensive approach for network attack forecasting. Computers \& Security, 58, pp.83-105. 
https://ics-cert.us-cert.gov/advisories/ICSA-13-340-01

https://ics.sans.org/media/Media-report-of-the-BTC-pipeline-Cyber-Attack.pdf

Kalogridis, G., Sooriyabandara, M., Fan, Z. and Mustafa, M.A., 2014. Toward unified security and privacy protection for smart meter networks. IEEE Systems Journal, 8(2), pp.641-654.

Kaplan, S., Zlotin, B., Zusman, A. and Visnepolschi, S., 1999. New tools for failure and risk analysis: An introduction to anticipatory failure determination (AFD) and the theory of scenario structuring. Ideation International.

Katz, J.S., Allor, P.G., Dougherty, S.A., Duffy, S.P., Riccetti, S., Chantz, H.D., Kisch, M., Oxford, B.S. and Snowdon, J.L., 2016. Securing the electric power infrastructure. IBM Journal of Research and Development, 60(1), pp.9-1.

Kohout, K., 2011. Multi-level structure of anticipatory behavior in alife.

Kröger, W. and Zio, E., 2011. Vulnerable systems. Springer Science \& Business Media.

Kushner, D., 2013. The real story of Stuxnet. ieee Spectrum, 3(50), pp.48-53.

Kwon, C. and Hwang, I., 2016. Cyber attack mitigation for cyber-physical systems: hybrid system approach to controller design. IET Control Theory \& Applications, 10(7), pp.731-741. 
Langley, A., Smallman, C., Tsoukas, H. and Van de Ven, A.H., 2013. Process studies of change in organization and management: unveiling temporality, activity, and flow. Academy of Management Journal, 56(1), pp.1-13.

Lee, R.M., Assante, M.J. and Conway, T., 2014. German Steel Mill Cyber Attack. Industrial Control Systems, 30.

Lehtiranta, L., Junnonen, J.M., Kärnä, S. and Pekuri, L., 2015. The constructive research approach: Problem solving for complex projects. Designs, methods and practices for research of project management, p.95.

Loewengart, V., 2012. Anticipating a Catastrophic Cyber Attack.

Malashenko, E., Villarreal, C. and Erickson, J.D., 2012. Cybersecurity and the Evolving Role of State Regulation: How it Impacts the California Public Utilities Commission.

Masys, A.J., 2012. Black swans to grey swans: revealing the uncertainty. Disaster Prevention and Management: An International Journal, 21(3), pp.320-335.

http://www.mcafee.com/us/resources/reports/rp-aspen-holding-line-cyberthreats.pdf http://www.mediacollege.com/journalism/news/newsworthy.html money.cnn.com/2015/08/05/technology/aramco-hack/

National Institute of Standards and Technology, 2014. Retrieved from: https://www.nist.gov/cyberframework 
National Institute of Standards and Technology, 2016. Retrieved from:

https://www.nist.gov/news-events/news/2016/11/new-nist-guide-helps-small-businessesimprove-cybersecurity

North American Electric Reliability Corporation public disclosure, 2012. Retrieved from: http://www.nerc.com/fileUploads/File/Events\%20Analysis/A-2012-05-07-

01_Ruggedcom_Unauthorized_Access_Vulnerability.pdf

Pellerin, K., 2003. Multimode verification system using fingerprint and speech information.

Proseanic V, Tananko D, Visnepolschi S., 2000. The experience of the Anticipatory Failure Determination (AFD) method applied to an Engine Concern. TRIZCON2000, Mayl.

https://www.publicsafety.gc.ca/cnt/ntnl-scrt/crtcl-nfrstrctr/index-en.aspx

Ralethe, S.G., 2015. Investigating common SCADA security vulnerabilities using penetration testing. Doctoral dissertation.

Rawal, B.S., Liang, S., Loukili, A. and Duan, Q., 2016. Anticipatory cyber security research: An ultimate technique for the first-move advantage. TEM Journal, 5(1), pp.314.

Regazzoni D., Russo D., 2010. TRIZ Tools to Enhance Risk Management, In Proceedings of the 10th ETRIA World TRIZ Future Conference. Bergamo, Italia, 3-5 November. ISBN: 978-88-96333-59-4. 
Rosen, R. 1985. Anticipatory systems. Philosophical, mathematical and methodological foundations, New York: Pergamon Press.

Srivastava, A., Morris, T., Ernster, T., Vellaithurai, C., Pan, S. and Adhikari, U., 2013. Modeling cyber-physical vulnerability of the smart grid with incomplete information. IEEE Transactions on Smart Grid, 4(1), pp.235-244.

Sunday, E., 2014. Extension and modification of anticipatory failure determination approach based on I-TRIZ. Doctoral dissertation, University of Stavanger.

Syed, Z., Finin, T., Padia, A. and Mathews, L., 2015. Supporting Situationally Aware Cybersecurity Systems.

Teixeira, A., Sou, K.C., Sandberg, H. and Johansson, K.H., 2015. Secure control systems: A quantitative risk management approach. IEEE Control Systems, 35(1), pp.24-45.

Trivellato, D. and Murphy, D., 2016. Lights out! Who’s next?.

Tweed, K., 2014. Attack on Nine Substations Could Take Down U.S. Grid. Retrieved from: http://spectrum.ieee.org/energywise/energy/the-smarter-grid/attack-on-ninesubstations-could-take-down-us-grid.

Van Heerden, R.P., Irwin, B. and Burke, I., 2012, January. Classifying network attack scenarios using an Ontology. In Proceedings of the 7th International Conference on Information-Warfare \& Security (ICIW 2012) (pp. 311-324).

Wang, W. and Lu, Z., 2013. Cyber security in the Smart Grid: Survey and challenges. Computer Networks, 57(5), pp.1344-1371. 
Wangen, G., 2015. The Role of Malware in Reported Cyber Espionage: A Review of the Impact and Mechanism. Information, 6(2), pp.183-211.

Weiss, M. and Bailetti, T., 2015, June. Value of open source projects: A case for open source cybersecurity. In 2015 IEEE International Conference on Engineering, Technology and Innovation/International Technology Management Conference (ICE/ITMC) (pp. 1-8). IEEE.

http://www.zdnet.com/article/off-the-grid-thousands-exposed-after-database-leak/

Zhioua, S., 2013, July. The Middle East under Malware Attack Dissecting Cyber Weapons. In 2013 IEEE 33rd International Conference on Distributed Computing Systems Workshops (pp. 11-16). IEEE.

Zio, E., 2016 a. Challenges in the vulnerability and risk analysis of critical infrastructures. Reliability Engineering \& System Safety, 152, pp.137-150.

Zio, E., 2016 b. Critical infrastructures vulnerability and risk analysis. European Journal for Security Research, pp.1-18. 


\section{Appendices}

\section{Appendix A. Template for failure analysis(AFD-1) retrieved from Kaplan et al. (1999)}

Step 1. Formulate the original problem

Describe the original situation associated with the undesired phenomenon:

There is a system called \{name of the system] for [describe purpose of system]. An undesired effect occurs under the conditions [describe]. It is necessary to find the cause of the phenomenon.

Step 2: Identify the success scenario

\begin{tabular}{|l|l|}
\hline Operation or process & Results \\
\hline & \\
\hline
\end{tabular}

Step 3: Localize the failure

Step 4: Formulate and amplify the inverted problem

Step 1. It is necessary to produce [describe inverted problem] under the given condition [describe]

Step 2. It is necessary to produce [describe inverted problem] under the given conditions [describe amplified condition].

Step 5. Search for solutions

The same phenomenon is intentionally created in the following area:

The resources (available or derived) are: 
The way(s) to produce the desired phenomenon as found in the innovation Guide are:

ARIZ for failure analysis

Step 1: The general way to produce the desired phenomenon is:

The secondary problem is:

Step 2: The ideal condition for realizing this harmful phenomenon are:

Step 3: The known way to provide the ideal condition is:

The way to change the system, recommended by the Innovation Guide is:

Step4:

A- Limitations to providing the ideal conditions are:

B- Contradiction: There is a way to produce the harmful effect but it cannot be realized for the following reason:

C- According to the Separation Principle, this condition may be resolved in the following way:

Step 6: Formulate Hypothesis and test for verifying them

The hypotheses are:

Tests required to verify the hypotheses:

Step 7: Correct the failure

The way to prevent /eliminate this kind of failure in the future is: 


\section{Appendix B. Template for failure prediction (AFD-2) retrieved from Kaplan et al. (1999)}

Step 1: Formulate the inverted problem

Describe the original situation associated with the undesired phenomenon:

There is a system called [name of the system] for [describe purpose of the system]. We wish to find all possible undesired effects or failures that can occur within, or as result of, this system, and to identify the ways in which these undesired phenomena can occur.

Step 2: Identify the success scenario

\begin{tabular}{|l|l|}
\hline Operations or phases & Results \\
\hline & \\
\hline
\end{tabular}

Step 3: Formulate the inverted problem

There is a system called [name of the system] for [describe]. It is necessary to produce all possible undesired effects or failures that can occur within, or as a result of, this system.

Step 4: Apparent ways to deteriorate the system function

Obvious possible initiating events are:

Obvious harmful end states are:

Obvious possible risk scenarios are:

Step 5: Identify available resources 
Substances:

Field resources:

Space resources:

Time resources:

Functional resources:

Systematic resources:

Change resources:

Differential resources:

Inherent resources:

Organizational resources:

Small failures disturbances:

Hazardous elements:

Control devices:

Protection systems:

Step 6: Utilize the knowledge base

Typical weak and dangerous zones in a system:

Typical functional failures:

Typical harmful impacts on systems (humans included):

Typical life cycle stages of technological systems:

Typical dangerous periods in system functioning and evolution:

Typical sources of high danger:

Typical disturbances in flows of substance, energy and information: 
Resources:

Step 7. Invent new solutions

The way(s) to produce the harmful effects according to the Innovation Guide are: ARIZ for failure prediction

Step 1: The general way to produce the desired effect is: The resulting secondary problem is:

Step 2: The ideal conditions for realizing this harmful effects are:

Step 3: The known way to provide the ideal condition is:

Step 4: The way to change the system, as recommended by the Innovation Guide, is:

A- Limitations to providing the ideal conditions are:

B- Contradiction- There is a way to produce the harmful effect but it cannot be realized for the following reason:

C- According to the Separation Principles, this contradiction may be resolved in the following ways:

Step 8: Intensify and mask harmful effects

Typical ways to intensify harmful effects:

Typical ways to mask harmful effects:

Step 9: Analyze the revealed harmful effects

Step 10: Prevent/eliminate the harmful effects 
Typical ways to prevent harmful effects:

Results of working with I-TRIZ operators: 


\section{Appendix C}

Failure analysis of the past cyber failures conducted by developing scenario trees according to the provided descriptions in Chapter 4, to identify the resources that indicated or contributed to the cyber failures.

\section{Aurora}

Figure C. 1 and Table C. 1 respectively providing the failure analysis and identified resources of the Aurora cyber failure.

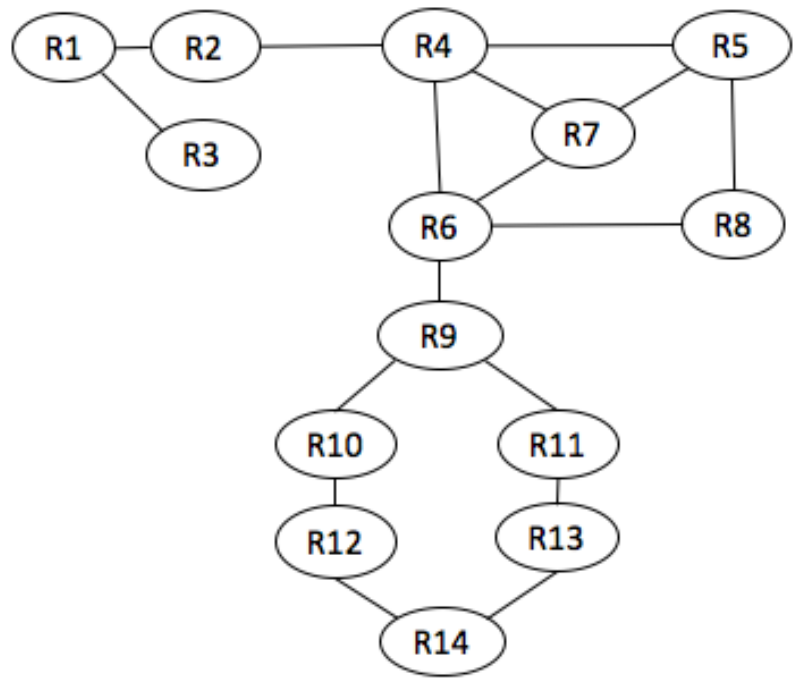

Figure C. 1-Failure analysis (scenario tree) for Aurora cyber failure 


\begin{tabular}{|l|l|l|}
\hline $\begin{array}{l}\text { Resource } \\
\text { No. }\end{array}$ & Resource Description & Typology \\
\hline R1 & Generator destroyed & Indicator \\
\hline R2 & \multicolumn{1}{|c|}{$\begin{array}{r}\text { Out of synchronism connection of the } \\
\text { genator to the grid }\end{array}$} & Vulnerability \\
\hline R3 & Generator & Tool \\
\hline R4 & Open and close breaker quickly & Way \\
\hline R5 & Insider with access & People \\
\hline R6 & $\begin{array}{l}\text { Command to the breakers manipulated via } \\
\text { unauthorized access }\end{array}$ & Way \\
\hline R7 & Breaker, or breakers, or connected relays & Tool \\
\hline R8 & Insider knowledge & People \\
\hline R9 & Old encryption standards & Vulnerability \\
\hline R10 & Dial-up connection vulnerabilities & Vulnerability \\
\hline R11 & Ethernet connection vulnerabilities & Vulnerability \\
\hline R12 & MODBUS address scanner & Tool \\
\hline R13 & Port scanner & Tool \\
\hline R14 & $\begin{array}{l}\text { Knowledge about finger printing, } \\
\text { discovery, access, detection, connection } \\
\text { speed }\end{array}$ & Information \\
\hline
\end{tabular}

Table C. 1-List of the resource of the Aurora cyber failure identified based on the provided description 


\section{BTC-Pipeline}

Figure C. 2 and Table C. 2 respectively providing the failure analysis and identified resources of the BTC-Pipeline cyber failure.

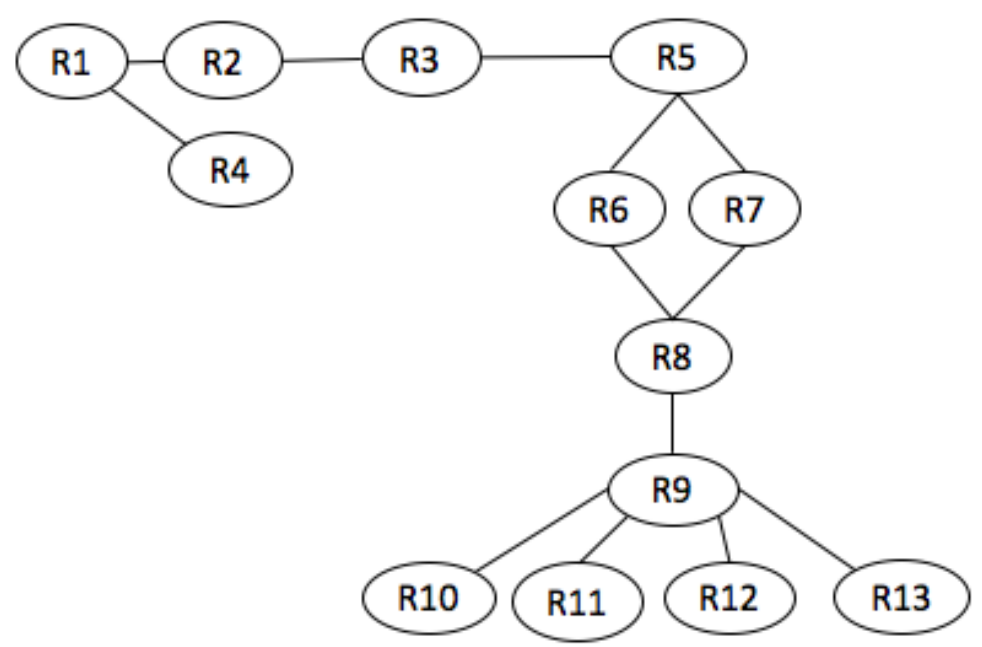

Figure C. 2- Failure analysis (scenario tree) for the BTC-Pipeline cyber failure 


\begin{tabular}{|l|l|l|}
\hline $\begin{array}{l}\text { Resource } \\
\text { No. }\end{array}$ & Resource Description & Typology \\
\hline R1 & $\begin{array}{l}\text { Images of two men with laptops near the } \\
\text { pipeline captured by an infrared camera from a } \\
\text { different network in the site }\end{array}$ & Indicator \\
\hline R2 & Two men with laptops near the pipeline station & People \\
\hline R3 & Physical access to camera & Way \\
\hline R4 & $\begin{array}{l}\text { Time of the image in infrared camera matched } \\
\text { with time of security breach }\end{array}$ & Information \\
\hline R5 & IP-based Camera & Tool \\
\hline R6 & $\begin{array}{l}\text { Network design vulnerability( penetration from } \\
\text { surveillance network to ICS network) }\end{array}$ & Vulnerability \\
\hline R7 & IP base camera vulnerability & Vulnerability \\
\hline R8 & $\begin{array}{l}\text { Software Installed for unauthorized access in } \\
\text { future }\end{array}$ & Way \\
\hline R9 & Old encryption standards & Vulnerability \\
\hline R10 & $\begin{array}{l}\text { Gas pressure increase in small station to } \\
\text { explode the pipeline }\end{array}$ & Way \\
\hline R11 & 60 hours of surveillance videos erased & Indicator \\
\hline R12 & Alarms shut down & Indicator \\
\hline R13 & Communication cut off & Indicator \\
\hline R14 & Backup satellite jammed & Indicator \\
\hline Table C 2- Listoftheresource ofthe BTC-Pipeline cyber failure identified based on the provided description & \\
\hline
\end{tabular}




\section{Stuxnet}

Figure C. 3 and Table C. 3 respectively providing the failure analysis and identified resources of the Stuxnet cyber failure.

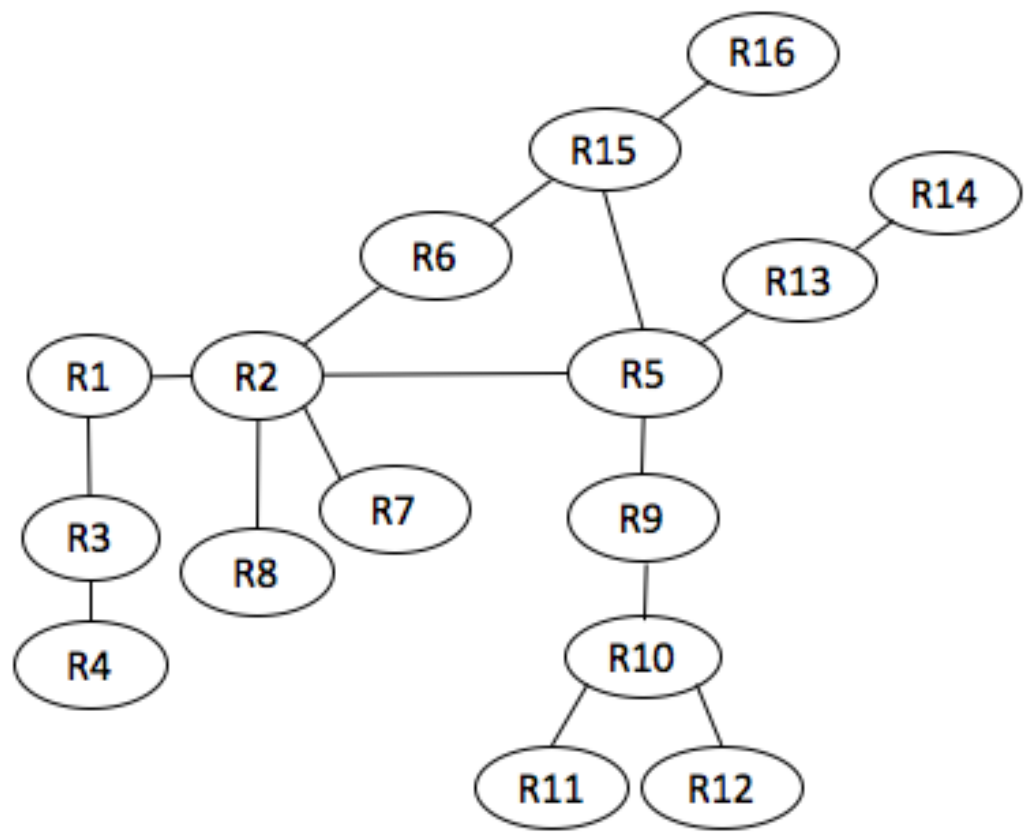

Figure C. 3- Failure analysis (scenario tree) for the Stuxnet cyber failure

\section{\begin{tabular}{|l|l} 
Resource & Resource Description
\end{tabular}}




\begin{tabular}{|l|l|l|}
\hline No. & & \\
\hline R1 & Centrifuges' abnormality & Indicator \\
\hline R2 & $\begin{array}{l}\text { Manipulated data in Siemens Step 7 software that } \\
\text { changed motors' speed in centrifuges }\end{array}$ & Way \\
\hline R3 & Manipulated data in alarms and control systems & Way \\
\hline R4 & $\begin{array}{l}\text { Alarm and sensors vulnerability to unauthorized } \\
\text { access (vulnerable security system) }\end{array}$ & Vulnerability \\
\hline R5 & Microsoft Windows vulnerability & Vulnerability \\
\hline R6 & Command and Control server (C\&C) & Tool \\
\hline R7 & Insider with knowledge & People \\
\hline R8 & Siemens Step 7 software vulnerability & Vulnerability \\
\hline R9 & $\begin{array}{l}\text { Self-copying codes to spread via network shared } \\
\text { points to make unauthorized access to lockdown } \\
\text { computers used to program PLCs }\end{array}$ & Way \\
\hline R10 & $\begin{array}{l}\text { Shared point in the system (vulnerable topology } \\
\text { design) }\end{array}$ & Vulnerability \\
\hline R11 & LNK shortcuts of USB sticks & Tool \\
\hline R12 & Print spooler of shared printer & Tool \\
\hline R13 & SQL server & Tool \\
\hline R14 & $\begin{array}{l}\text { IP and model of PLC responsible to control motor } \\
\text { frequency converters in centrifuges }\end{array}$ & Information \\
\hline R15 & LAN and network & Tool \\
\hline R16 & Stakeholders network & Tool \\
\hline
\end{tabular}

Table C. 3-List of the resource of the Stuxnet cyber failure identified based on the provided description 


\section{RuggedCom}

Figure C. 4 and Table C. 4 respectively providing the failure analysis and identified resources of the RuggedCom cyber failure.

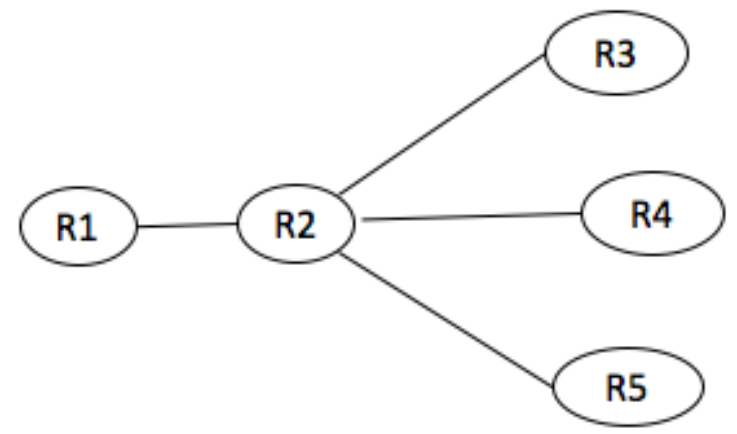

Figure C. 4- Failure analysis (scenario tree) for the RuggedCom cyber failure

\begin{tabular}{|l|l|l|}
\hline $\begin{array}{l}\text { Resource } \\
\text { No. }\end{array}$ & Resource Description & Typology \\
\hline R1 & RuggedCom products before 2012 & Indicator \\
\hline R2 & Unauthorized access to RuggedCom devices & Way \\
\hline R3 & Weak cryptography for password (Backdoor) & Vulnerability \\
\hline R4 & Online Scripts & Information \\
\hline R5 & Mac address of devices & Information \\
\hline
\end{tabular}

Table C. 4- List of the resource of the RuggedCom cyber failure identified based on the provided description 


\section{Flame}

Figure C. 5 and Table C. 5respectively providing the failure analysis and identified resources of the Flame cyber failure.

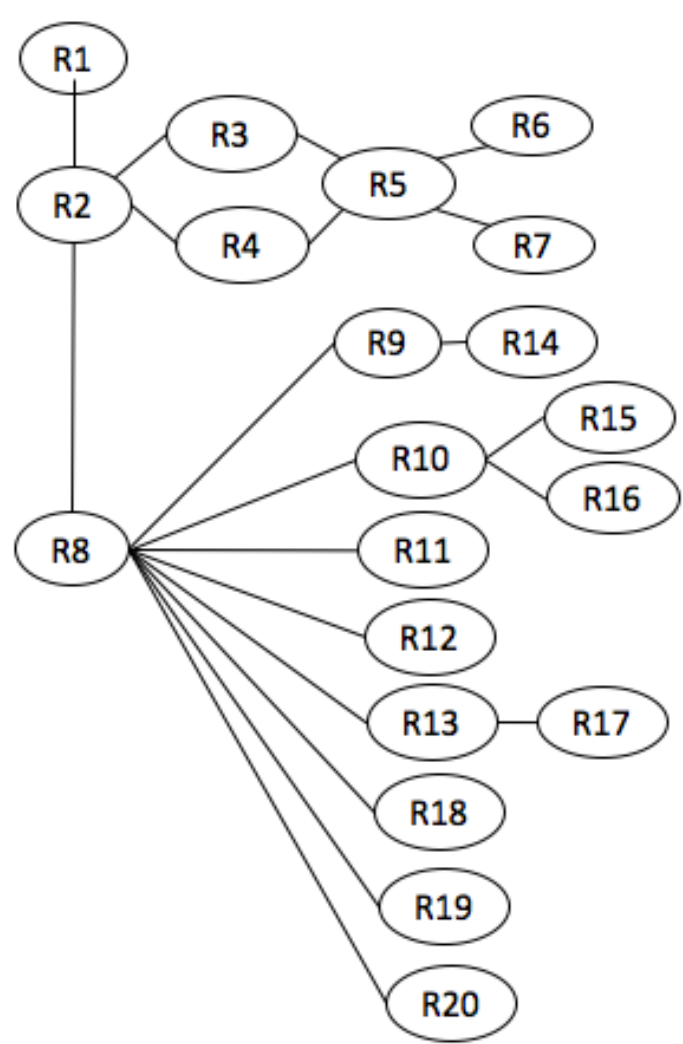

Figure C. 5- Failure analysis (scenario tree) for the Flame cyber failure 


\begin{tabular}{|c|c|c|}
\hline $\begin{array}{l}\text { Resource } \\
\text { No. }\end{array}$ & Resource Description & Typology \\
\hline R1 & $\begin{array}{l}\text { Russia-based antivirus firm Kaspersky Lab that } \\
\text { found the worm }\end{array}$ & Indicator \\
\hline $\mathrm{R} 2$ & $\begin{array}{l}\text { Cyber worm that made unauthorized system-level } \\
\text { access to lockdown computers }\end{array}$ & Way \\
\hline R3 & $\begin{array}{l}\text { Fake proxy for Windows update to bypass security } \\
\text { mechanism }\end{array}$ & Way \\
\hline R4 & Multiple propagation and code injection methods & Tool \\
\hline R5 & Microsoft Windows vulnerability & Vulnerability \\
\hline R6 & LNK shortcuts of USB sticks & Tool \\
\hline R7 & Print spooler of shared printer & Tool \\
\hline R8 & Modules to conduct espionage attacks & Way \\
\hline R9 & Module to take Screenshots & Tool \\
\hline R10 & $\begin{array}{l}\text { Modules to record audio from environment by } \\
\text { switching on microphone, web camera or from skype } \\
\text { conversation }\end{array}$ & Tool \\
\hline R11 & Modules to browse through attached storage devices & Tool \\
\hline R12 & $\begin{array}{l}\text { Modules to spy PDF, AutoCAD files to steal top } \\
\text { secret information and extract geolocation from } \\
\text { images }\end{array}$ & Tool \\
\hline R13 & Modules for log keystrokes & Tool \\
\hline R14 & Monitors & Tool \\
\hline R15 & Web camera & Tool \\
\hline R16 & Microphone & Tool \\
\hline R17 & Keyboards & Tool \\
\hline R18 & $\begin{array}{l}\text { Modules to compress, encrypt and save information } \\
\text { in a database }\end{array}$ & Tool \\
\hline R19 & $\begin{array}{l}\text { Modules to perform Bluetooth function to map } \\
\text { devices in area }\end{array}$ & Tool \\
\hline $\mathrm{R} 20$ & $\begin{array}{l}\text { Modules to spy the network traffic and send data to } \\
\text { C\&C server in small packages via Bluetooth or } \\
\text { network }\end{array}$ & Tool \\
\hline
\end{tabular}

Table C. 5-List of the resource of the Flame cyber failure identified based on the provided description 


\section{German Power Utility (50 Hertz)}

Figure C. 6 and Table C. 6 respectively providing the failure analysis and identified resources of the German Power Utility (50 Hertz) cyber failure.

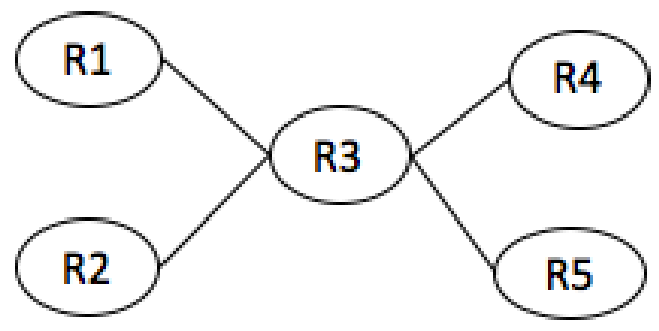

Figure C. 6- Failure analysis (scenario tree) for the German Power Utility (50 Hertz) cyber failure

\begin{tabular}{|l|l|l|}
\hline $\begin{array}{l}\text { Resource } \\
\text { No. }\end{array}$ & Resource Description & Typology \\
\hline R1 & Emails' disruption & Indicator \\
\hline R2 & Internet domains' blockage & Indicator \\
\hline R3 & Distributed Denial of Service & Way \\
\hline R4 & Network & Vulnerability \\
\hline R5 & Botnet & Tool \\
\hline $\begin{array}{l}\text { Table C. 6- List of the resource of the German Power Utility (50 Hertz) cyber failure identified based on the provided } \\
\text { description }\end{array}$
\end{tabular}


Aramco

Figure C. 7 and Table C. 7 respectively providing the failure analysis and identified resources of the Aramco cyber failure.

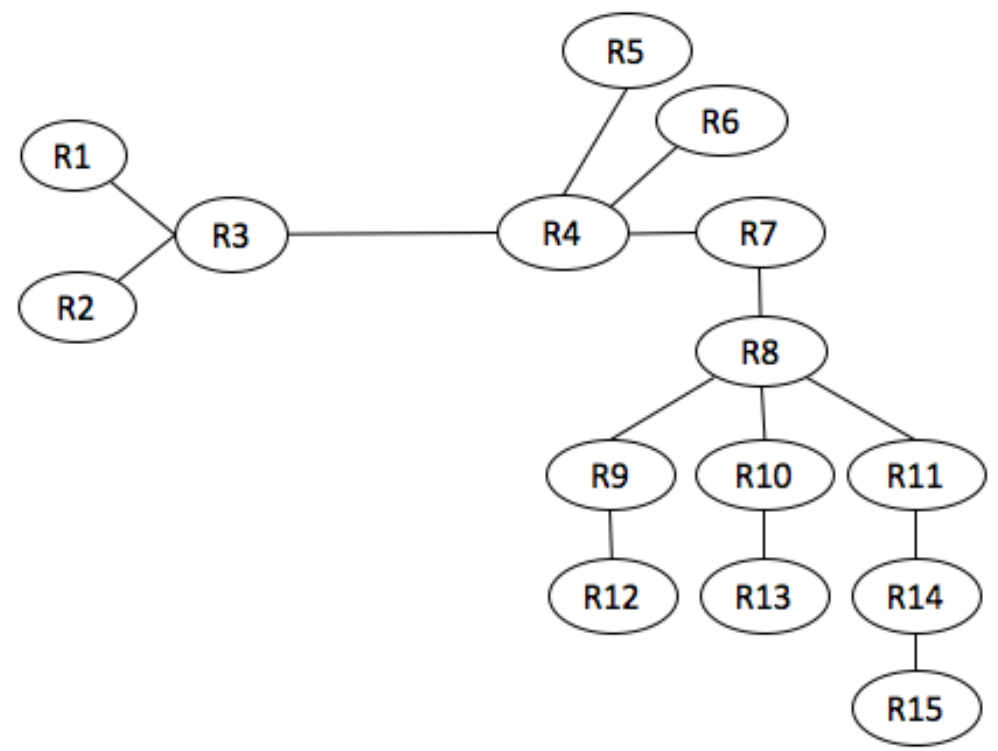

Figure C. 7- Failure analysis (scenario tree) for the Aramco cyber failure 


\begin{tabular}{|l|l|l|}
\hline $\begin{array}{l}\text { Resource } \\
\text { No. }\end{array}$ & Resource Description & Typology \\
\hline R1 & Disappeared files & Indicator \\
\hline R2 & Fail in 30,000 computers & Indicator \\
\hline R3 & Network vulnerability & Vulnerability \\
\hline R4 & Respond to a phishing email & Way \\
\hline R5 & Email contained malicious link to install malware & Tool \\
\hline R6 & Insider who responded to phishing email & People \\
\hline R7 & Security mechanism vulnerability & Vulnerability \\
\hline R8 & Shamoon malware (modular) & Tool \\
\hline R9 & $\begin{array}{l}\text { Dropper module to install the malware via } \\
\text { unauthorized access to other components }\end{array}$ & Tool \\
\hline R10 & Reporter module to send data & Tool \\
\hline R11 & Wiper module to copy, rewrite and delete files & Tool \\
\hline R12 & Codes to make unauthorized access & Way \\
\hline R13 & HTTP Get request & Tool \\
\hline R14 & $\begin{array}{l}\text { Target files with names of download, document, } \\
\text { picture, music, video, desktop }\end{array}$ & Way \\
\hline R15 & Master boot records to destroy the disk sector & Tool \\
\hline
\end{tabular}

Table C. 7- List of the resource of the Aramco cyber failure identified based on the provided description 


\section{German Steel Factory}

Figure C. 8 and Table C. 8 respectively providing the failure analysis and identified resources of the German Steel Factory cyber failure.

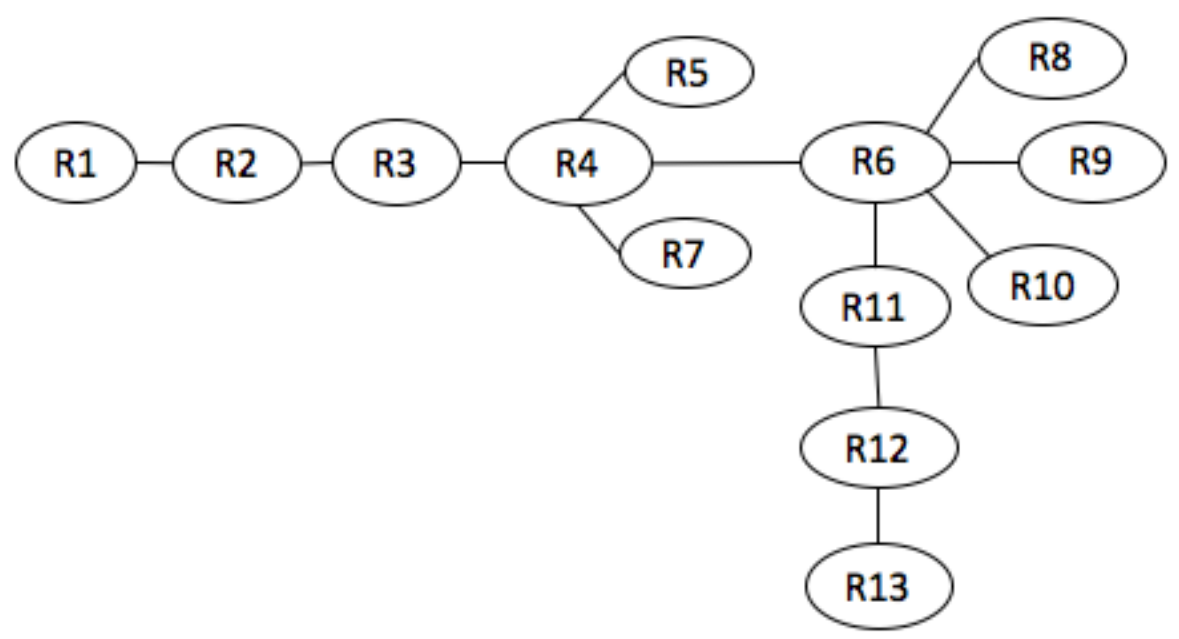

Figure C. 8-Failure analysis (scenario tree) for the German Steel Factory cyber failure 


\begin{tabular}{|l|l|l|}
\hline $\begin{array}{l}\text { Resource } \\
\text { No. }\end{array}$ & Resource Description & Typology \\
\hline R1 & Furnace cannot be shutdown & Indicator \\
\hline R2 & Breakdown in ICS system function & Indicator \\
\hline R3 & Codes to manipulate data in ICS & Way \\
\hline R4 & Codes to make unauthorized access to ICS network & Way \\
\hline R5 & $\begin{array}{l}\text { Vulnerabilities in Active Directory were used to } \\
\text { make unauthorized access to ICS network }\end{array}$ & Vulnerability \\
\hline R6 & Small set of workstations' vulnerabilities & Vulnerability \\
\hline R7 & ICS knowledge & Information \\
\hline R8 & Key logger & Tool \\
\hline R9 & Network scanner & Tool \\
\hline R10 & Self-executing codes & Tool \\
\hline R11 & Vulnerabilities in security mechanism & Vulnerability \\
\hline R12 & Insider who responded to phishing email & People \\
\hline R13 & $\begin{array}{l}\text { Respond to the email with a compromised PDF file } \\
\text { attached }\end{array}$ & Way \\
\hline
\end{tabular}

Table C. 8- List of the resource of the German Steel Factory cyber failure identified based on the provided description 


\section{Ukrainian Electrical Grid}

Figure C. 9 and Table C. 9 respectively providing the failure analysis and identified resources of the Ukrainian Electrical Grid cyber failure.

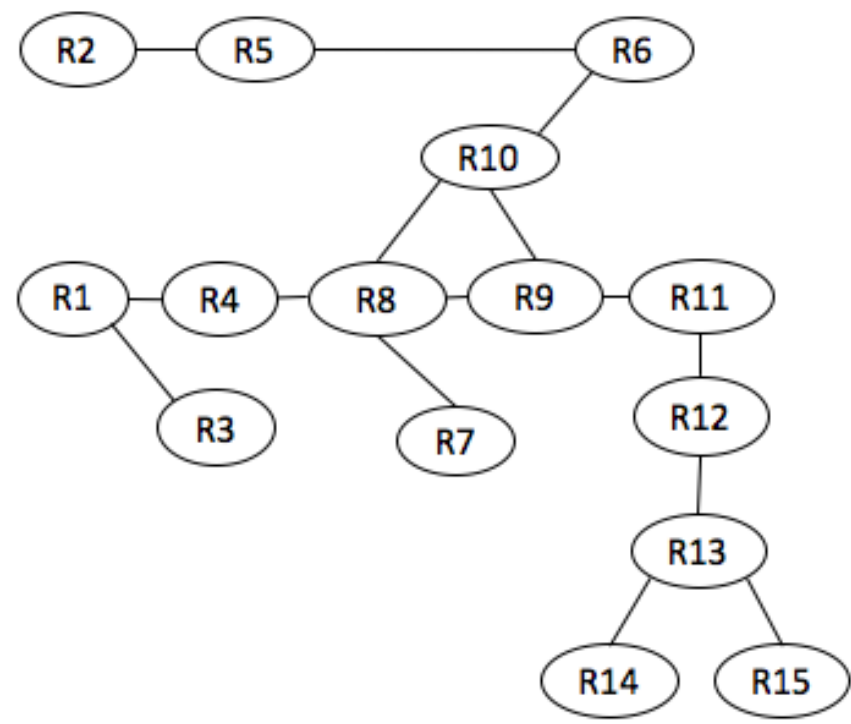

Figure C. 9- Failure analysis (scenario tree) for the Ukrainian Electrical Grid cyber failure 


\begin{tabular}{|l|l|l|}
\hline $\begin{array}{l}\text { Resource } \\
\text { No. }\end{array}$ & Resource Description & Typology \\
\hline R1 & $\begin{array}{l}\text { Disconnection of seven } 110 \mathrm{kV} \text { substations and } \\
\text { twenty-three } 35 \mathrm{kV} \text { substations from the grid and } \\
\text { malfunctioning in two utilities }\end{array}$ & Indicator \\
\hline R2 & Problem in call center & Indicator \\
\hline R3 & Direct commands to breakers & Way \\
\hline R4 & $\begin{array}{l}\text { Codes to manipulate data in SCADA used to open } \\
\text { the breakers }\end{array}$ & Way \\
\hline R5 & DOS attack to call center & Way \\
\hline R6 & Delay awareness process at control station & Way \\
\hline R7 & $\begin{array}{l}\text { Codes to disable ICS response and restart } \\
\text { commands to prevent fixing the problem }\end{array}$ & Way \\
\hline R8 & Backdoor in SCADA components & Vulnerability \\
\hline R9 & $\begin{array}{l}\text { Security mechanism vulnerabilities (penetration } \\
\text { from main server to ICS ) }\end{array}$ & Vulnerability \\
\hline R10 & $\begin{array}{l}\text { Codes to disable sensors and alarms to prevent } \\
\text { staff from sighting the problem }\end{array}$ & Way \\
\hline R11 & $\begin{array}{l}\text { Codes to allow unauthorized access to the } \\
\text { network }\end{array}$ & Way \\
\hline R12 & $\begin{array}{l}\text { Respond to the email contained an Excel file } \\
\text { attached }\end{array}$ & Way \\
\hline R13 & Insider who responded to a phishing email & People \\
\hline R14 & BlackEnergy malware campaign & Tool \\
\hline R15 & KillDisk malware & Tool \\
\hline $\begin{array}{l}\text { Table C.9- List of the resource of the Ukrainian Electrical Grid cyber failure identified based on the provided } \\
\text { description }\end{array}$ & & \\
\hline
\end{tabular}




\section{Kingo Database}

Figure C. 10 and Table C. 10 respectively providing the failure analysis and identified resources of Kingo Database Grid cyber failure.

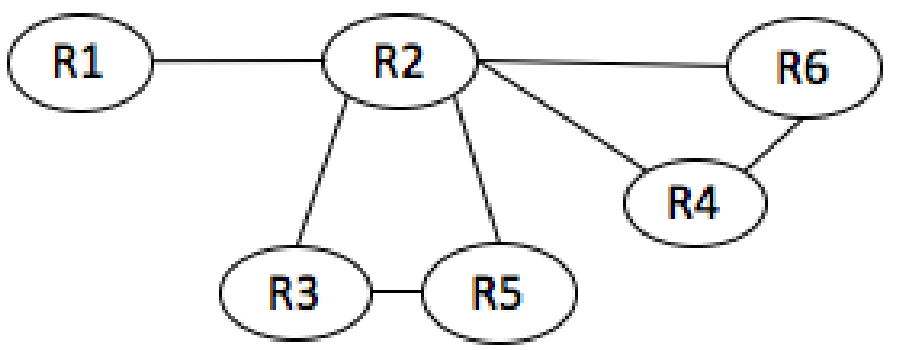

Figure C. 10- Failure analysis (scenario tree) for the Kingo Database cyber failure

\begin{tabular}{|l|l|l|}
\hline $\begin{array}{l}\text { Resource } \\
\text { No. }\end{array}$ & Resource Description & Typology \\
\hline R1 & MacKeeper security research team & Indicator \\
\hline R2 & Unprotected database saved on the cloud & Vulnerability \\
\hline R3 & Professional search engines such as Shodan.io & Tool \\
\hline R4 & Energy start-up customers & People \\
\hline R5 & $\begin{array}{l}\text { Human rights violation (murder or private } \\
\text { surveillance) }\end{array}$ & Way \\
\hline R6 & $\begin{array}{l}\text { Confidential data (18,800 customers' full name, } \\
\text { address, exact GPS location of home, occupation, } \\
\text { cell phone number, unique state identification } \\
\text { number, sex, marital status, nationality, the } \\
\text { birthplace, and some pictures, finger prints and } \\
\text { signatures) }\end{array}$ & Information \\
\hline
\end{tabular}

Table C. 10- List of the resource of the Kingo Database cyber failure identified based on the provided description 